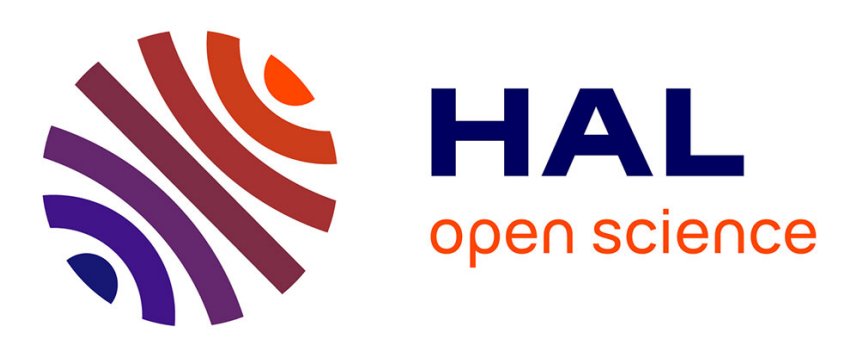

\title{
Experimental settlement and dynamic behavior of a portion of ballasted railway track under high speed trains
}

Ali Al-Shaer, Denis Duhamel, Karam Sab, Gilles Forêt, Laurent Schmitt

\section{To cite this version:}

Ali Al-Shaer, Denis Duhamel, Karam Sab, Gilles Forêt, Laurent Schmitt. Experimental settlement and dynamic behavior of a portion of ballasted railway track under high speed trains. Journal of Sound and Vibration, 2008, 316, pp.211-233. 10.1016/j.jsv.2008.02.055 . hal-00309048

\section{HAL Id: hal-00309048 \\ https://hal.science/hal-00309048}

Submitted on 6 Aug 2008

HAL is a multi-disciplinary open access archive for the deposit and dissemination of scientific research documents, whether they are published or not. The documents may come from teaching and research institutions in France or abroad, or from public or private research centers.
L'archive ouverte pluridisciplinaire HAL, est destinée au dépôt et à la diffusion de documents scientifiques de niveau recherche, publiés ou non, émanant des établissements d'enseignement et de recherche français ou étrangers, des laboratoires publics ou privés. 


\title{
Experimental settlement and dynamic
}

\section{behavior of a portion of ballasted railway track under high speed trains}

\author{
A. Al Shaer ${ }^{\text {a }}$, D. Duhamel ${ }^{\mathrm{a}, 1}, \mathrm{~K}$. Sab ${ }^{\mathrm{a}}$, G. Foret $^{\mathrm{a}}$ and \\ L. Schmitt ${ }^{b}$ \\ ${ }^{a}$ Université Paris Est, Institut Navier, \\ 6 et 8 Avenue Blaise Pascal, \\ Cité Descartes, Champs sur Marne, \\ 77455 Marne-la-Vallée, cedex 2, France \\ ${ }^{\mathrm{b}} \mathrm{SNCF}$ - Direction Innovation $\&$ Recherche \\ Physique du Système Ferroviaire et Confort \\ 45 rue de Londres \\ 75008 Paris, France
}

Total number of pages $=65$

Total number of figures $=25$

Total number of tables $=5$ 


\section{Abstract}

The study of railway tracks under high speed trains is one of the most important researches in the domain of transport. A reduced scale experiment with three sleepers is presented to study the dynamic behavior and the settlement of ballasted tracks. A large number of trains passing at high speeds are simulated by signals, applied with the help of hydraulic jacks, having the shape of the letter $\mathrm{M}$ and representing the passages of bogies on sleepers. This experiment offers results such as displacements, accelerations, pressures and settlements that allow to better understand the dynamic behavior of a portion of a ballasted railway track at reduced scale and to estimate the settlement versus the number of load cycles. It was found that mechanical properties such as the global stiffness of the track can have important variations during the experiment. The settlement was also found to be a function of the acceleration of sleepers and above all it was observed, for accelerations above a critical value, that the increase of settlement per cycle was very high.

Key words: railway track, ballast, high speed, experiment, reduced scale, dynamics, settlement, acceleration.

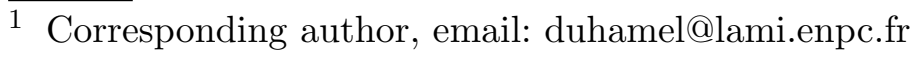




\section{Introduction}

The study of railway tracks is one of the most important researches in the domain of transport. Railway companies try to increase the rolling speed of trains in order to meet the high solicitations of this mean of transport in the domain of travelling as well as in the domain of freights. Tracks submitted to high speed trains demand high budgets in order to fulfil the costs of maintenance required in order to return the track to its initial position.

Indeed, when the track is loaded by the weight of the train, the ballast and the layers below can undergo a non elastic displacement. During the unloading, the initial geometry is not exactly recovered and small residual displacements are obtained. After several cycles, the accumulation of these small settlements lead to a modification of the geometry of the track. Two phases of settlement can be observed. Immediately after the tamping, heavy trains are passed on the track to increase the density of the ballast. The settlement is fast until the ballast is well compacted. During the second phase the settlement is slower and increases regularly with the number of cycles. In this paper we are mainly interested in this second phase.

Most of settlement laws are obtained by real or reduced scale experiments. Authors try to understand the behavior of the second phase of settlement because the first phase lasts a few number of cycles and is quite dependent on the way the tamping is made. One of the earliest experiments in this domain is the triaxial test. We can cite the triaxial tests realized by M.J.Shenton [1] on samples of ballast. He obtained a settlement law which has the following 
form:

$$
\tau_{N}=\tau_{1}[1+C \log N]
$$

where $C$ is a constant, $\tau_{1}$ is the settlement of the first cycle and $\tau_{N}$ the settlement at cycle $N$. Such tests can be suitable for materials made of small particles such as sand for which the size of particles is infinitesimal with respect to the volume of the sample, but for ballast they cannot really reproduce the behavior of a real track which has a small number of grains under the sleepers.

In Japan, Sato [2] was able to find an experimental relation from measurements made by a vehicle over several years. His relation has the following form:

$$
S=2.09 \times 10^{-3} \times T^{0.31} \times V^{0.98} \times M^{1.1} \times L^{0.21} \times P^{0.26}
$$

where $S$ is the increase of track irregularities ( $\mathrm{mm} / 100$ per day), $T$ is the load (million tons/year), $V$ is the mean velocity of the trains $\left(\mathrm{km} \mathrm{h}^{-1}\right), L$ is an influence parameter of the rails ( $L=1$ for welded rails and $L=10$ for rails assembled by joints, $P$ is another influence parameter $(P=1$ for a good soil and $P=10$ for a bad one) and $M$ is a structural parameter given by

$$
M=P_{b} y_{z} S_{i}
$$

where $P_{b}$ is the quasi static pressure in the ballast, $y_{z}$ is the acceleration of the rail and $S_{i}$ is an impact coefficient which depends on the rail properties.

In other experiments made at the technical University of Munchen [3], three settlement laws were obtained:

$$
\tau_{\text {opt }}=1.57 p \Delta N_{a}+3.04 p^{1.21} \log N_{a}
$$




$$
\begin{gathered}
\tau_{\text {pess }}=2.33 p \Delta N_{a}+15.2 p^{1.21} \log N_{a} \\
\tau_{\text {med }}=1.89 p \Delta N_{a}+5.15 p^{1.21} \log N_{a}
\end{gathered}
$$

Here, the settlement is classified according to three levels: an optimistic level $\tau_{\text {opt }}$, a pessimistic level $\tau_{\text {pess }}$ and an average level $\tau_{\text {opt }} . N_{a}$ is the number of axles passing on the track and $p$ the pressure in the ballast. The first part of each relation is the initial settlement in the few cycles after the tamping while the second part is the long term settlement.

In addition, the results obtained by these experiments depend on the boundary conditions of the sample. One of the earliest experiments that more reflects the reality is an experiment of one sleeper at real scale realized by M.Balsan in 1980 [4]. This experiment studied the behavior of a portion at real scale under static loading. Others took into account the effect of the moving loads and tried to understand the behavior of railway tracks by installing measurement instruments on existing tracks $[2,5]$.

Other authors made experiments at reduced scale. With an experiment at reduced scale, one can better control his experiment and its components, one can also repeat the experiment several times with different modifications, with more results and less time. We can cite the experimental work of X.Oviedo which aimed at understanding the behavior of ballast during the process of tamping [6]. This experiment represents a box containing a layer of microballast with a block of concrete placed just above this layer. The aim is to vibrate laterally the ballast by sinusoidal loads at different frequencies at one side in order to fill the void between the ballast and the block. On the opposite side a static loading is applied on the sample. From force-displacement results 
obtained at the side where the static force is applied, X.Oviedo had concluded that ballast has different behaviors: solid, visco-elastic and fluid for increasing frequencies of excitation.

Another experiment was realized by N.Guérin [7] which consisted of a concrete block placed on a micro-ballast layer which was supported by a layer of elastomer simulating the elastic behavior of an infinite half-space at $100 \mathrm{MPa}$. Signals applied on the block are of shape $\mathrm{M}$ and they represent the passage of bogies on a block of a sleeper. Different experiments lead to the following law:

$$
\frac{d \tau}{d N}=\alpha d^{\beta}
$$

where $\frac{d \tau}{d N}$ is the increase in settlement per cycle, $d$ is the elastic deflection of the sleeper and $\alpha$ and $\beta$ are parameters. This law was obtained for velocities until 250km h $\mathrm{h}^{-1}$. V.Bodin [8] improved the previous experiment and replaced the block of concrete by a sleeper (bi-blocks) at reduced scale. Lateral loading were also allowed. Laws similar to (7) were obtained both for vertical and lateral settlements (with different parameters $\alpha$ and $\beta$ ). It was also observed that the settlement increases a lot in some cases.

From the numerical point of view, most researchers try to predict elastic responses of railway tracks under the passing of trains using more or less complicated numerical models. These models are generally validated with respect to experimental results. Among the simple models, one can mention models represented by several systems (mass-spring-damper) [9], a beam supported by Winkler foundations [10] and a beam on an infinite half-space [11]. These simple models can be turned more complicated by modelling the vehicle and 
the wheel-rail contact. These models cannot offer sufficient information about the behavior of the railway tracks since they do not represent precisely the structure of the railway track, but on the other hand they can be useful to predict displacements of rails and to study the influence of certain critical parameters such as speeds and frequencies on the dynamic behavior of the structure. Other models are three-dimensional and can take into account the non linearity of some materials such as ballast [12]. Another numerical approach was considered by M.Abdelkrim et al. [13]. This law gives the settlement at a point, for $N$ cycles, from permanent deformations which can be obtained from the plastic behavior of the materials on one cycle.

So there are a few number of settlement laws obtained in the past. They considered mainly trains with limited velocities and often with a simplified model of a real track, for example without soil and with only the ballast layer. In this paper we propose an experiment that takes into account the effect of soil and that of moving loads by using three sleepers instead of one. In this experiment, we simulate high speed trains that can attain $400 \mathrm{~km} \mathrm{~h}^{-1}$ on the contrary of most experiments which simulate or study tracks under moderated speeds that do not rise above $300 \mathrm{~km} \mathrm{~h}^{-1}$. We start this paper by presenting the experiment, the laws of similitude, the applied forces, the experiment plan and its metrology. We then try to identify soil and the complete structure (soil, ballast and sleepers) behaviors depending on the experimental results. Finally, we present new results on the settlement and we show that it depends strongly on the acceleration in the structure. A critical acceleration appears above which the settlement increments become very high. 


\section{Experiment description}

An experiment at reduced scale $(1 / 3)$ which represents a portion of a ballasted railway track with three sleepers (bi-blocks) has been built in order to simulate the passage of a rolling load on the portion as shown in Fig. 1. These sleepers are loaded with the help of three hydraulic jacks that provide signals having the shape of the letter M. These loads are applied on the sleepers with a shift in time depending on the rolling speed. This experiment permits to evaluate the response of ballasted railway tracks due to the passage of high speed trains.

The portion includes, from bottom to top, a layer of soil (untreated gravels) of $0.6 \mathrm{~m}$ height compacted in three layers of $0.2 \mathrm{~m}$ each, a layer of compacted micro-ballast ( $0.1 \mathrm{~m}$ equivalent to $0.3 \mathrm{~m}$ at real scale) on which three sleepers are placed with respect to the positions of the hydraulic jacks, wedges made of steel installed on each sleeper in order to transmit loads applied by the jacks to the blocks and a layer of non compacted micro-ballast which is added until the upper surface of the blocks $(0.08 \mathrm{~m})$. The distance between two sleepers is $0.2 \mathrm{~m}$ at reduced scale corresponding to the real distance of $0.6 \mathrm{~m}$ at real scale. It is supported by a solid mass that contains from top to bottom, a horizontal steel plate of $0.07 \mathrm{~m}$ thickness, a layer of reinforced concrete $(1 \mathrm{~m})$ and a layer of sand $(2.5 \mathrm{~m})$. This solid mass constituted of different materials is considered as an infinite half-space [14].

The ballast layers are limited on two opposite sides by inclined planes (slopes) that represent free edges. The other sides are limited by vertical steel plates $(0.05 \mathrm{~m})$ representing the beginning and the end of the portion. The hydraulic jacks are fixed on a steel frame which is bolted on the horizontal steel plate. 
All components of the experiment (portion and solid mass) are located on a reinforced concrete foundation able to support the important weights of these components.

\subsection{Similitude laws: conservation of the acceleration}

Since we are interested in the dynamic behavior of the railway track, it is important to adopt a similitude conserving the acceleration. In this similitude law, we choose to realize experiments at reduced scale $(1 / 3)$ with natural materials whose physical and mechanical properties are conserved.

The equation of elasto-dynamic equilibrium can be written as follows:

$$
\operatorname{div}(\boldsymbol{\Sigma})+\mathbf{F}_{v}=\rho . \ddot{\mathbf{U}} \quad \text { in }(\Omega)
$$

where $\rho$ is the density, $\ddot{\mathbf{U}}$ represents the acceleration, $\Sigma$ is the stress tensor, $\operatorname{div}($.$) represents the divergence operator, \mathbf{F}_{v}$ is the density of body forces and $\Omega$ represents the studied domain.

The homogeneity of this formula imposes that the product $\rho \ddot{\mathbf{U}}$ (inertia forces) must have the same scale factor as that of the density of body forces $\mathbf{F}_{v}$ and the derivative of stresses with respect to the length $L$. The dimension of the divergence operator (div) is $L^{-1}$ and since $\mathbf{F}_{v}$ and $\rho \ddot{\mathbf{U}}$ are conserved and the length $L$ is divided by 3, the scale factor of length, the stress tensor must be divided by 3 . Time must be divided by $\sqrt{3}$ at reduced scale in order to conserve the acceleration. By a simple reasoning, all other scale factors can be determined by respecting the equation of dynamics, some of them are summarised in table 1. 
Since we use natural materials whose physical and mechanical characteristics are conserved, we can deduce that the stress tensor must be kept, which is in contradiction with the above equation requiring that this tensor must be divided by 3 . In practice a phenomenon help us to reduce this obstacle, the non linear behavior of ballast offers a lower tangent elasticity modulus at reduced scale than at real scale, in addition the forces applied at reduced scale are 27 times less than those at real one.

\subsection{Applied force: cyclic load}

The experiments consist in simulating the passages of trains on three sleepers by applying signals, on every sleeper with a certain shift in time, reproducing the passage of a bogie. Since trains are composed of several bogies it is obvious to apply several signals successively. Every cycle corresponds to the passage of a bogie. The applied signal has the shape of the letter $M$ where each peak corresponds to the load exerted by an axle of a bogie. According to Sauvage's calculations [15] that do not take into account the dynamic loading and their adaptation by A.Alaoui and T.Naciri [16] as an analytical continuous relation, one can represent the vertical force exerted by the rail on a block due to the passage of a bogie at real scale by the following function:

$$
F(t, Q, v)=\frac{Q Y}{2}\left[X^{\left(\frac{v t-a}{d}\right)^{2}}+X^{\left(\frac{v t-a-L}{d}\right)^{2}}\right]
$$

where $Q$ is the load supported by an axle (N) (17 tons), $v$ is the speed of the train $\left(\mathrm{m} \mathrm{s}^{-1}\right), t$ is the time $(\mathrm{s}), d$ is the distance between two consecutive sleepers ( $d=0.6 \mathrm{~m}$ at real scale), $a$ is a critical distance ( $a=3 \mathrm{~m}$ that equals $5 d), L$ is the distance between the two axles of a bogie $(L=3 \mathrm{~m}), X$ and $Y$ 
are variables without units varying between 0 and 1 , their values depend on the elasticity modulus of soil and are presented in table 2. The coefficient $Y$ depends only on the stiffness of the soil located under the ballast layer. The coefficient $X$ is determined by fitting the analytical function $F(t, Q, v)$ with respect to Sauvage's results for adjacent sleepers of the most loaded sleeper.

Supposing that the load is the same on the two beams of the rail, the expression of the force exerted by the jack on each block of a sleeper at reduced scale is therefore:

$$
F_{1 / 3}(t, Q, v)=\frac{Q Y}{2 \times 27}\left[X^{\left(\frac{v t-a}{d}\right)^{2}}+X^{\left(\frac{v t-a-L}{d}\right)^{2}}\right] \quad t \in\left[0, T_{1 / 3}\right]
$$

where $T_{1 / 3}=\frac{d_{b}}{\sqrt{3} v}$ and $d_{b}=18.7 \mathrm{~m}$ represents the distance between two consecutive bogies at real scale. Fig. 2 presents the force exerted on a block due to the passage of a bogie for $v=100 \mathrm{~m} \mathrm{~s}^{-1}, X=0.64$ and $Y=0.38$.

Signals of shape M are provided experimentally by hydraulic jacks. A hydraulic jack permits to generate important forces that can reach $100 \mathrm{kN}$, in our case the jack's capacity is $24.19 \mathrm{kN}$ in statics and $18.1 \mathrm{kN}$ in dynamics which is sufficient to apply forces with a law of similitude conserving the acceleration for which $F_{\max } \approx 3 \mathrm{kN}$. An important property of a hydraulic jack is its capacity to excite low frequencies (0.5 to $200 \mathrm{~Hz}$ ).

\subsection{Experiment metrology}

Different transducers are installed in the portion of the railway track at reduced scale in order to measure forces, accelerations, displacements and pressures. Force and displacement transducers are integrated in each hydraulic 
jack. Six force and six displacement transducers are installed on the blocks of the three sleepers to measure vertical loads and displacements as shown in Fig. 3. Two accelerometers are installed on the blocks of the central sleeper in order to measure their vertical accelerations. Four accelerometers are drowned in the ballast, they are placed at the level of the base of blocks in the middle of two successive sleepers. These accelerometers and their cables are protected by aluminium tubes as shown in Fig. 3. A pressure transducer is installed in soil at $0.06 \mathrm{~m}$ below its upper surface, under each block of the central sleeper in order to measure vertical pressures. A temperature transducer is inserted at mid-height of the soil layer.

\subsection{Experiment plan}

A typical experiment consists in generating signals of shape $M$ with three sleepers in order to simulate the passage of trains on the portion. It contains several packages of cycles where each cycle corresponds to the passage of a bogie and each package consists of 200000 cycles realized at a certain rolling speed. The portion is loaded by packages of signals or cycles at increasing rolling speeds of values $160,210,270,320,360$ and $400 \mathrm{~km} \mathrm{~h}^{-1}$.

Additional experiments called "identification experiments" are realized on soil and on the complete structure (soil, ballast and sleepers). At the beginning and at the end of each typical experiment, identification experiments are realized on soil during the setting up, before adding the first layer of ballast and at the end of the typical experiment after removing the sleepers and ballast as shown in Fig. 4. Identification experiments are also realized on the complete structure at the beginning and between packages before changing the rolling 
speed and at the end of an experiment.

An identification experiment allows to study soil and complete structure behaviors. It consists in generating, using only the central jack, several cycles of sinusoidal forces at 10,1 and $0.1 \mathrm{~Hz}$ with three different magnitudes $F / 3$, $2 F / 3$ and $F$ for each frequency and several static loading and dis-loading with a maximum magnitude $F$ where $F$ represents the maximum value of a signal of shape $\mathrm{M}(F \approx 3 \mathrm{kN})$. Typical experiments are repeated several times in order to verify that one can get close experimental results.

\subsection{Piloting software}

The piloting software is elaborated under LABVIEW, an environment recommended by National instruments that is compatible with the acquisition cards. It allows to send signals (excitations) to jacks and to receive other signals (responses) through acquisition cards to which all transducers are connected. All experiments are piloted by displacements. Each experiment is started by an approach step. This approach consists in determining the preliminary stiffness of the portion necessary to guess the displacement signal to be imposed by the jacks in order to obtain the desired force signal. The calculation of this stiffness requires two points $P_{i}\left(u_{i}, f_{i}\right)$ where $u_{i}$ is the displacement imposed by the jack and $f_{i}$ is the force measured by the force transducer integrated in this jack. Experiments can be programmed using graphical interface windows where users can choose several columns of data to be realized. In each column, users can select the type of signal to apply (sinusoidal or of shape M), the number of jacks to excite (one or three jacks), the speed of trains and the number of cycles, a cycle corresponds to the passage of a bogie, in the case of 
a signal of shape $\mathrm{M}$.

Data measured by each transducer are saved in a text file having the same name as the transducer. An acquisition is done every five minutes in the case of a signal of force of $\mathrm{M}$ shape and every two seconds in the case of a sinusoidal signal. Every measurement corresponding to a period and representing the passage of a bogie is obtained with one hundred twenty sampling points. The sampling frequency can be written as follows:

$$
f_{s}=\frac{N_{p}}{T_{b}}
$$

where $N_{p}=120$ is the number of sampling points for a measurement window and $T_{b}$ is the period of the passage of a bogie on a sleeper at reduced scale.

The maximum frequency of excitation can be expressed by the following formula:

$$
f_{e}=\frac{1}{T_{a}}
$$

where $T_{a}$ is the period of the passage of an axle on a sleeper at reduced scale, $T_{a} \approx T_{b} / 6$

This number of sampling points seems suitable in our case because the sampling frequencies, varying from $494 \mathrm{~Hz}$ for $v=160 \mathrm{~km} \mathrm{~h}^{-1}$ to $1235 \mathrm{~Hz}$ for $v=400 \mathrm{~km} \mathrm{~h}^{-1}$, are greater than 10 times the maximum frequencies of excitation which are $26 \mathrm{~Hz}$ to $64 \mathrm{~Hz}$ at reduced scale. 


\subsection{Post-processing software}

The post-processing software is elaborated under MATLAB (7) with graphical user interfaces as shown in Fig. 5. This software includes several buttons where each one corresponds to a transducer and reads the measurement files already recorded by the piloting software. It allows to draw several curves for a given number of measurements, to filter these curves in case of noisy signals, to determine the Fourier transform of a signal, to draw settlement curves in terms of the number of cycles in the case of a displacement measurement, to determine the increment of settlement per cycle and to do linear and non linear interpolations. In addition, it presents complete information concerning every measurement, such as the date, hour, rolling speed or frequency of excitation, number of excited jacks, etc...All treated or extracted data can be saved in binary files FiLE.MAT to be used subsequently.

\section{Dynamic behavior of the track}

\subsection{Soil behavior}

This section consists in identifying the soil of our experiments. This identification allows to understand the behavior of soil with the help of experiments realized on soil that offer displacements associated to applied forces on its upper surface. Displacements and forces are measured respectively by displacement and force transducers integrated in the central jack.

It is clear that the behavior of soil in statics and in dynamics according to force- 
displacement results is non linear. The force-displacement ratio, in other words the stiffness, is not constant. Soil stiffness seems to increase as the applied forces increase. The equivalent elasticity modulus of soil can be determined by considering that the soil layer simulates an infinite half-space. It is known that for a linear elastic half-space, one has [17]:

$$
E_{s}=\frac{\left(1-\nu^{2}\right) F}{2 a \bar{u}}
$$

where $F$ is the total force due to an imposed average displacement $\bar{u}$ on a circular section of radius $a$ at the upper surface of soil and $\nu$ is the Poisson's ratio. The values $\nu=0.25$ and $a=0.08 \mathrm{~m}$ are used in the following.

The elasticity modulus of soil which is proportional to the stiffness is variable. Relations between the elasticity modulus and the associated force are non linear as it is shown in Fig. 6, for forces superior to $500 \mathrm{~N}$ these relations become linear. At the beginning of a typical experiment, in statics, for a force of $500 \mathrm{~N}$ one gets a mean elasticity modulus of $25 \mathrm{MPa}$ while for a force 4 times larger one gets a mean elasticity modulus of $35.5 \mathrm{MPa}\left(E_{2000 N} \approx 1.4 \times E_{500 N}\right)$. At the end of an experiment, for a force of $500 \mathrm{~N}$ one gets a mean elasticity modulus of 26.5 MPa while for a force 4 times larger one gets a mean elasticity modulus of $38 \mathrm{MPa}\left(E_{2000 N} \approx 1.4 \times E_{500 N}\right)$.

In dynamics, under a sinusoidal excitation at $10 \mathrm{~Hz}$, one notices that the force-displacement hysteresis loops are large. The damping capacity of soil increases as the area of these loops increases. During four settings up of soil, one gets approximately the same area for the four loops which is normal since we have always the same soil. From a loop (force-displacement) associated to one period of a sinusoidal loading at $10 \mathrm{~Hz}$, one can estimate the damping 
ratio of soil using the following formula [18]:

$$
\xi=\frac{D}{4 \pi U_{d}}=19.6 \%
$$

where $D$ represents the dissipated energy per cycle $\left(D=\int_{1 \text { cycle }} F d u\right)$, its value is equal to the area of the loop in Fig. 7 (a) and $U_{d}$ represents the total energy of deformation $\left(U_{d}=\frac{1}{2} F_{\max } u_{\max }\right)$ which is equal to the area of the triangle in Fig. 7 (b).

Since the difference between the stiffnesses of soil for the four experiments does not rise above $10 \%$, we can consider that soil has the same stiffness for all experiments. We notice at the end of each typical experiment that the stiffness of soil increases by $10 \%$ with respect to the initial one at the beginning of each experiment.

\subsection{Complete structure behavior}

The identification of the complete structure (soil, ballast and sleepers) consists in studying the evolution of the static and dynamic stiffnesses of the portion for every experiment with respect to the number of cycles. The tools necessary in order to reach the aim of this section are the identification experiments realized on the complete structure.

In Fig. 8 the force displacement curves for the complete structure are plotted at three different instants in an experiment. These instants are chosen for three different velocities just before their respective 200000 cycles of load. The results are similar to figure 6 and show a small rigidification of the structure as the magnitude of the load increases. It can also be seen some variations in 
the response but the global behavior is however not very different at the three instants.

Fig. 9 presents the progress of the typical experiments (1), (2), (3) and (4). In the case of experiments (3) and (4), 200000 cycles at $380 \mathrm{~km} \mathrm{~h}^{-1}$ are done, which explains the difference between the total number of cycles between these experiments and the first two experiments (1) and (2). Since identification experiments consist in applying several signals by the central jack, all parameters and experimental results presented so on correspond to the left block of the central sleeper.

The static stiffness shown in Fig. 10 for each experiment is variable with respect to the number of cycles (the static stiffness for experiment (1) at 600000 cycles is not shown in this figure because we did not get measurements corresponding to the same loading magnitude at which all stiffnesses of experiments (2), (3) and (4) are determined). According to the results of experiments (2) and (3) for example, the stiffness increases until a certain value then it decreases and it increases again to reach a maximum value at 1 million cycles and at the end it decreases to a value that can be close to its initial one at zero cycle. At the end of every typical experiment, the complete structure may have a weak stiffness on the contrary of what one can expect.

The maximum static stiffnesses obtained during the experiment are 1.88, 1.36, 1.48 and 1.26 times more elevated than the initial one at zero cycle for experiments (1), (2), (3) and (4) respectively. At zero cycle, at the beginning, complete structures of experiments (1) and (2) have the same static stiffness. The gap between their stiffnesses starts to increase with the number of cycles and at the end the ratio between these stiffnesses equals 1.06. At the begin- 
ning, the static stiffness of the complete structure of experiment (4) is 1.08 times larger than that of experiment (3). At the end, the complete structures of the two experiments seem to have the same stiffness.

Fig. 11 shows the dynamic stiffness in terms of the number of cycles for the four typical experiments (1), (2), (3) and (4) according to forces and displacements measured at the left block of the central sleeper. This dynamic stiffness corresponds to a sinusoidal loading at $10 \mathrm{~Hz}$ with a magnitude of $1500 \mathrm{~N}$. The dynamic stiffness of experiments (1) and (2) have the same tendency to increase with the number of cycles till 800000 cycles. At one million cycles the ratio between the stiffnesses of these two experiments reaches 1.35. These experiments seem to have the same stiffness at the beginning as well as at the end. The stiffnesses of experiments (3) and (4) are variable according to the number of cycles. These last experiments seem to have nearly the same dynamic stiffness at the end. The maximum dynamic stiffness is 1.67, 1.4, 1.34 and 1.63 times larger than the initial stiffness at zero cycle for experiments (1), (2), (3) and (4) respectively.

The differences between the stiffnesses of the four experiments at zero cycle can be explained by the fact that ballast was compacted manually, so it is difficult to maintain the same level of compacting and anyway the granular structure is different for each experiment. In order to evaluate the dynamic effect, we can compare the static and the dynamic stiffnesses obtained for an experiment. Fig. 12 shows the difference between the two stiffnesses of experiment (3). The most elevated ratio between these two stiffnesses in the presented example can reach 1.4.

In Fig. 13, we present the elastic displacements at the left block of the central 
sleeper in terms of the rolling speed, under the passage of a bogie. Each displacement, corresponding to a certain speed, is the average value of maximum elastic displacements measured during the passage of 200000 bogies. We try to explain the differences between the displacements measured with respect to the four experiments from the curves of static and dynamic stiffnesses. The curves of stiffnesses allow to have a preliminary idea about the differences in displacements but do not permit to quantify these differences because the stiffness of the structure can vary during the 200000 passages of bogies for the same rolling speed and also because the dynamic stiffnesses are obtained for sinusoidal forces at $10 \mathrm{~Hz}$ while the complete structures behavior depends on the frequency of excitation. It is clear that identification experiments offer information about the behavior of the complete structure before and after each 200000 cycles but to know what happens during each cycle, it is necessary to supervise the variation of displacements during these cycles.

For a rolling speed of $160 \mathrm{~km} \mathrm{~h}^{-1}$, the differences between the displacements for the four experiments can be explained by the differences between their static stiffnesses. For the speeds of $210 \mathrm{~km} \mathrm{~h}^{-1}$ and $270 \mathrm{~km} \mathrm{~h}^{-1}$, the differences between the dynamic stiffnesses can explain the differences between the displacements. From $320 \mathrm{~km} \mathrm{~h}^{-1}$ and after, it is difficult to explain the displacement differences by differences according to static or dynamic stiffnesses.

\subsection{Numerical results}

A simple finite element model was also built in order to compare numerical results to experimental ones. We try, by using dynamic calculations, to predict the elastic response of the portion at reduced scale under the passages of 
trains at rolling speeds varying from $160 \mathrm{~km} \mathrm{~h}^{-1}$ to $400 \mathrm{~km} \mathrm{~h}^{-1}$. All experiment components are considered as linear elastic materials. Ballast, which is a granular medium, is supposed to be a continuous one that follows a linear elastic constitutive law. It is known that ballast has a non-linear behavior, for this reason we decompose it into two regions of different physical and mechanical characteristics. Ballast in the zones under the blocks at an angle $\alpha=45^{\circ}$ is considered as compacted $\left(\rho=1700 \mathrm{~kg} \mathrm{~m}^{-3}, E=200 \mathrm{MPa}\right.$ and $\left.\nu=0.4\right)$ while ballast elsewhere is considered as un-compacted $\left(\rho=1300 \mathrm{~kg} \mathrm{~m}^{-3}, E=8 \mathrm{MPa}\right.$ and $\nu=0.2$ ). This assumption is taken due to several experimental observations emphasising that stresses are totally localised in the zone located under the blocks. A global damping matrix of Rayleigh type is used.

We propose to simulate the experiment by a three-dimensional model using the finite element code CESAR-LCPC elaborated by laboratoire central des ponts et chaussées. Since the experiment has a symmetrical shape, a half part is modelled as shown in Fig. 14 and normal displacements in the plane of symmetry are blocked.

In our model, wedges made of steel that are used to distribute loads on the two blocks of each sleeper are not modelled for reasons of simplicity and especially because forces applied by these wedges are measured by force transducers located on every block just below the support of each wedge. The frame, supporting the jacks, and all components located below the soil layer are not modelled. We consider the horizontal steel plate as rigid so it is sufficient to block all vertical displacements at the base of the soil layer. Vertical plates limiting the vertical sides of the portion are also considered as rigid so we block all normal displacements of these sides. The ties connecting the two blocks of each sleeper are modelled by three-dimensional solid finite elements 
by conserving their bending stiffness $\left(E I=E^{\prime} I^{\prime}\right)$ and their mass distribution $\left(\rho S=\rho^{\prime} S^{\prime}\right)$. Forces applied on the model represent signals of shape M measured by the three force transducers on the three blocks constituting a half of the portion. They are uniformly distributed on rectangular sections $\left(0.11 \times 0.097 \mathrm{~m}^{2}\right)$ at the middle of each block.

Numerical results are obtained for parameters such as displacements and accelerations. They are determined using the three-dimensional finite element model (linear and elastic) already presented in section 3. The structure is excited with forces of shape $\mathrm{M}$ for different rolling speeds. As it is shown in section 3.1, soil has a non linear behavior, in other words for each force one can get an equivalent elasticity modulus. The equivalent elasticity modulus of soil to be introduced in our three-dimensional model can be determined using Eq. (13) by considering that the soil layer simulates an infinite half-space and with respect to mean pressures measured in soil at $0.06 \mathrm{~m}$ below its upper surface during experiments under passing bogies from $160 \mathrm{~km} \mathrm{~h}^{-1}$ to $400 \mathrm{~km} \mathrm{~h}^{-1}$. So in order to determine the equivalent elasticity modulus we need to determine the total force applied on the soil in order to generate the same pressures measured in soil during typical experiments. The total force obtained due to an imposed displacement on a circular section of radius $a$, can be given by the following formula:

$$
F=\int_{0}^{a} 2 \pi r P_{0}\left(1-\frac{r^{2}}{a^{2}}\right)^{-1 / 2} d r=2 \pi a^{2} P_{0}
$$

where $P_{0}$ is the minimum pressure at the circular section due to an imposed displacement.

Knowing the formula of the vertical stress at a point $P(x, y, z)$ under a con- 
centrated load $F_{c}$ exerted at the surface of an infinite half-space (Boussinesq solution):

$$
\sigma_{z z}=\frac{-3 F_{c} z^{3}}{2 \pi\left(r^{2}+z^{2}\right)^{5 / 2}}
$$

where $r=\sqrt{x^{2}+y^{2}}$, one can deduce the vertical stress determined for an imposed displacement on a circular section of radius $a$ at a depth $z$ under the centre of the circular section [17]:

$$
\sigma_{z z}=P_{m}=-3 P_{0} \int_{0}^{a} \frac{r z^{3}}{\left(r^{2}+z^{2}\right)^{5 / 2}\left(1-\frac{r^{2}}{a^{2}}\right)^{1 / 2}} d r
$$

where $P_{m}$ is the maximum measured pressure in soil at $0.06 \mathrm{~m}$ below its upper surface, in our case we have $x=y=0, z=0.06 \mathrm{~m}$ and $a=0.08 \mathrm{~m}$. Using the previous equation, we can determine $P_{0}$ and then deduce the total force $F$ using Eq. (15). Now, knowing the magnitude of the total force, one can find the associated displacement $\bar{u}$ with the help of the identification experiments on soil and therefore, the equivalent elasticity modulus of soil can be determined using Eq. (13). The mean value $E=33 \mathrm{MPa}$ was found.

We consider that the whole model has the same damping ratio as that of the soil. Since we are interested in maximum responses, this ratio does not have a significant influence on the numerical results. We present in table 3 the physical and mechanical characteristics of all materials used in the calculations. Errors in the following tables stand for the relative error which is written as follows:

$$
\text { error }=\frac{\left|q_{m}-q_{c}\right|}{q_{m}} \times 100
$$

where $q$ is the concerned quantity and indices $m$ and $c$ stand for measured and calculated quantities. 
The results of the computations are presented in tables 4 and 5. A correct agreement can be observed between the measurements and the computations in most cases. More comments on these results are given below.

\subsection{Effect of the velocity of the load}

According to table 4, the finite element model shows good results concerning the maximum elastic displacements. The relative error varies from $8 \%$ to $21 \%$ except for the rolling speed of $270 \mathrm{~km} \mathrm{~h}^{-1}$ where it reaches $33.5 \%$. The structure under passing bogies at $270 \mathrm{~km} \mathrm{~h}^{-1}$ seems to be stiffer than it was before, under passing bogies at 160 and $210 \mathrm{~km} \mathrm{~h}^{-1}$, in other words at this stage of the experiment where speeds are relatively low the stiffness of the structure is more influenced by the number of cycles than by the rolling speed. This model seems also able to predict maximum positive accelerations at the left block of the central sleeper close to that obtained by experiments as shown in table 5 . Concerning vertical pressures in soil and accelerations in ballast, our model is not suitable to predict these parameters because it is not able to predict high contact forces that lead to high pressures in soil and because ballast is divided into two different zones.

In figure 15, the elastic displacement is plotted versus the rolling velocity. The mean values of tests $2,3,6,7,11,12,13$ and 15 are used. A regression with second degree polynomials is presented and provided a good estimate of the mean displacement versus the velocity. A minimum can be seen near $250 \mathrm{~km} \mathrm{~h}^{-1}$ which can be explained by a modification of the rigidity of the structure. In figures 10 and 11 one can observe that the rigidity of the structure increases for the first sets of 200000 cycles corresponding to the velocities up 
to $300 \mathrm{~km} \mathrm{~h}^{-1}$. It can also be seen in tables 4 and 5 that near $250 \mathrm{~km} \mathrm{~h}^{-1}$ the differences between the measurements and the computations are the largest because the rigidity of the ballast is different between the model and the reality.

The accelerations of sleepers, oriented upward or downward, increase with the velocity as can be seen in figure 16. The upward accelerations are larger than the downward and the difference between the two values increases with the velocity. The acceleration in ballast, presented in figure 17, follows similar trends.

\section{Settlement}

In the precedent section we were interested by the dynamic behavior of the track. Here results on the settlement of sleepers are presented. Moreover we try to link the settlement with mechanical parameters such as the acceleration. In the following figures all the parameters are presented at reduced scale excepted the velocity which is presented at real scale for a better link to the reality. The results are also presented for the central sleeper.

\subsection{Effect of the moving load}

Experiments are conducted with respectively one and three jacks at different rolling velocities. One or three sleepers are solicited on a large number of cycles. The aim is to study the effect of the moving load on the settlement. Figure 18 presents the settlement of the left block of the central sleeper versus the number of cycles for the velocities 160 and $320 \mathrm{~km} \mathrm{~h}^{-1}$. It can be clearly 
observed that the settlement under the action of three jacks is greater than for only one jack. So an experiment simulating a moving load is necessary to get a true estimate of the real settlement. The action of just one jack underestimates the real settlement. This can also be seen in figure 19 at $400 \mathrm{~km} \mathrm{~h}^{-1}$ for which the difference is still larger.

It can also be observed that at $400 \mathrm{~km} \mathrm{~h}^{-1}$ the settlement is not regular as for lower velocities. On the contrary the settlement is very fast for a short number of cycles and becomes much lower at other moments. These fast settlements come from the reorganisation of grains in the ballast layer. These violent reorganisations are followed by periods of slow movements of grains. The history of these reorganisations is different for the left and right sleepers because the time at which a reorganisation happens cannot be accurately predicted but depends on the precise arrangement of the granular media under each sleeper. The measurements show a little larger acceleration for right sleeper in case of three jacks which can be correlated to the larger settlement. It is also shown below that the standard deviation of the settlement increases strongly with the velocity of the load.

\subsection{Settlement law}

In figure 20, it is shown that the load velocity is linked to the increment of settlement of sleepers. A regression with second order polynomials also provides a good estimate of the global tendency.

One of the aims of the study is to find a law relating the settlement to mechanical parameters such as the acceleration for high velocities of the load. 
In figures 21 and 22, the settlement of the left and right blocks of the central sleeper versus the acceleration in ballast and on the sleepers respectively are presented. In figure 21, where the settlement increment is plotted versus the acceleration in ballast, it can be observed that when the upward and downward accelerations are greater respectively than $1.4 \mathrm{~g}$ and $2 \mathrm{~g}$ the settlement increment is very scattered and the mean value becomes approximately 15 times larger than for accelerations lower than these critical values. In a similar way in figure 22 in which the settlement increment is plotted versus the sleeper acceleration, it can be observed that when the upward and downward accelerations are greater respectively than $1 \mathrm{~g}$ and $2 \mathrm{~g}$ the settlement is also scattered and approximately 15 times larger than for lower accelerations.

\subsection{Scattering}

In the following the standard deviation of the settlement increment is studied. First it can be plotted versus the velocity of the load and secondly it can be studied as a function of the elastic deflection of sleepers or of the acceleration which is the true parameter describing the dynamic behavior of the structure. To study this standard deviation, it is important to deal with experimental data coming from identical tests. These are obtained from typical tests which are tests numbers $2,3,6,7,11,12,13$ and 15 .

The standard deviation is a parameter which estimates the reproducibility or repetitivity of our tests. It is given by

$$
s=\sqrt{\frac{\sum_{i=1}^{i=n}\left(x_{i}-\bar{x}\right)^{2}}{n-1}}
$$

where $n$ is the number of measurements, $x_{i}$ is the value of test number $i$ of a 
parameter such as the elastic displacement, the acceleration or the settlement increment, $\bar{x}$ is the average value over $n$ measurements given by $\bar{x}=\sum_{i=1}^{i=n} x_{i} / n$. In figure 23, the decimal logarithm of the standard deviation of the settlement increment and that of the standard deviation of the downward acceleration in ballast are plotted versus the velocity of the load. A linear regression can be found between the logarithm of the standard deviation of the settlement and the velocity when the velocity is less than $360 \mathrm{~km} \mathrm{~h}^{-1}$. Above $360 \mathrm{~km} \mathrm{~h}^{-1}$ the settlement increment shows a large scattering. A linear regression is also observed between the standard deviation of the downward acceleration and the velocity. At $400 \mathrm{~km} \mathrm{~h}^{-1}$ the standard deviation of the settlement is about ten times its value at $360 \mathrm{~km} \mathrm{~h}^{-1}$. For the acceleration the standard deviation at $400 \mathrm{~km} \mathrm{~h}^{-1}$ is about five times its value at $360 \mathrm{~km} \mathrm{~h}^{-1}$.

In figures 24 and 25 the decimal logarithm of the standard deviation of the settlement increment is plotted versus the average accelerations of the sleepers or of ballast in upward and downward directions. Linear regressions are also found in these cases. This means that if the accelerations of sleepers or in ballast are known, it is possible to estimate the standard deviation of the settlement from these curves.

\section{Conclusion}

A reduced scale experiment of three sleepers is presented in order to better understand the dynamic behavior of railway tracks, to identify the evolution of the mechanical properties of the tracks and the settlement of sleepers versus the number of cycles. This experiment is characterised by three important 
points:

(1) A natural soil is used to simulate the platform;

(2) Three sleepers are used to simulate moving loads due to passing trains at high speeds;

(3) With this experiment, the structure is submitted into high speeds reaching $400 \mathrm{~km} \mathrm{~h}^{-1}$.

Due to experimental results offered by this experiment, soil behavior is identified. It is clear that the behavior of soil in statics as well as in dynamics is non linear. Hence, its equivalent modulus of elasticity depends on the associated force. Using the measured pressures in soil obtained during experiments at different rolling speeds and considering that soil represents an infinite halfspace, a mean equivalent elasticity modulus is determined. Damping ratio of soil is also identified with respect to a sinusoidal loading at $10 \mathrm{~Hz}$. Concerning the behavior of the complete structure (soil, ballast and sleepers), it is noticed that stiffnesses (dynamic and static) are very variable in terms of the number of cycles. One can find a maximum static stiffness $88 \%$ larger than the initial one (at the beginning of the experiment), and a maximum dynamic stiffness $67 \%$ larger than the initial one. The dynamic effect can be noted by comparing the two static and dynamic stiffnesses where one can find a difference of $40 \%$.

Concerning the settlement increment, it was observed that its value depends strongly on the velocity of the load. An important parameter to estimate its value is the acceleration of sleepers or in ballast. Critical values are found between 1.4 and $2 \mathrm{~g}$ depending if we measure the accelerations of sleepers or in ballast and depending also of the direction of measurement. Above these critical values the settlement is much stronger. It is also observed a large scattering 
in the values of the mechanical parameters such as the elastic displacement, the acceleration or the settlement for large accelerations.

\section{References}

[1] M.J. Shenton, Deformation of railway ballast under repeated loading conditions, Pergamon press, Oxford, 1978.

[2] Y. Sato, Japanese studies on deterioration of ballasted track, Vehicle system dynamics, 24 (1995).

[3] S. Iwnicki, S. Grassie and W. Kik, Track settlement prediction using computer simulation tools. Vehicle System Dynamics Supplement, (1999) 37-46.

[4] M. Balsan, Un modèle mathématique de la voie ferrée moderne, Thèse de l'Ecole Nationale des Ponts et Chaussées (1980).

[5] L. Andersen, Wave propagation in infinite structures and media, PhD thesis, Aalborg university (2002).

[6] X. Oviedo-Marlot, Etude du comportement du ballast par un modèle micromécanique, Thèse de l'Ecole Nationale des Ponts et Chaussées (2001).

[7] N. Guérin, K. Sab and P. Moucheront, Identification expérimentale d'une loi de tassement du ballast, Canadian geotechnical journal, 36 (1998) 523-532.

[8] V. Bodin, Comportement du ballast des voies ferrées soumises à un chargement vertical et latéral, Thèse de l'Ecole Nationale des Ponts et Chaussées (2001).

[9] W.M. Zhai, K.Y. Wang and J.H. Lin, Modelling and experiment of railway ballast vibrations, Journal of sound and vibration, 270 (2004) 673-683.

[10] A.V. Metrikine and K. Popp, Vibration of a periodically supported beam on an elastic half-space, European journal of mechanics and solids, 18 (1998) 679-701. 
[11] X. Sheng, C.J.C. Jones and M. Petyt, Ground vibration generated by a load moving along a railway track, Journal of sound and vibration, 228 (1999) 129156.

[12] L. Hall, Simulations and analyzes of train-induced ground vibrations in finite element models, Soil dynamics and earthquake engineering, 23 (2002) 403-413.

[13] M. Abdelkrim, G. Bonnet, and P. Buhan. A computational procedure for predicting the long term residual settlement of a platform induced by repeated traffic loading. Computers and geotechnics, 30:463-476, January 2003.

[14] A. Al Shaer, D. Duhamel, K. Sab, G. Foret and L. Schmitt, Dimensionnement dynamique d'un banc d'essai de voie ferrée à échelle réduite par le code CESARLCPC, XIV ème Colloque Vibrations, chocs et bruit (Ecully, 2004).

[15] G. Sauvage, Railway track vertical static behavior, research report, INRETS / $\operatorname{LTN}(1993)$.

[16] A. Alaoui and T. Naciri, Les voies ballastées, Technical report: Rapport EUROBALT,CERAM,ENPC (1995).

[17] K.L. Johnson, Contact mechanics, Cambridge University Press (1992).

[18] C. Lalanne, Vibrations sinusoidales, Hermès science publication (1999). 


\section{List of Figures}

1 Experiment at reduced scale 36

$2 \quad$ Applied force at a block at reduced scale 37

$\begin{array}{lll}3 & \text { Transducers } & 38\end{array}$

$4 \quad$ Identification experiment on soil 39

$5 \quad$ Post-processing software 40

6 Elasticity modulus of soil: (a) at the beginning of experiment, (b) at the end of experiment : ○ Experiment (1), $\nabla$ Experiment (2), $\triangleright$ Experiment (3), $\diamond$ Experiment $(4) \quad 41$

7 (a): Dissipated energy per cycle, (b): Total energy of deformation 42

8 Force displacement on the complete structure for static loads

9 Progress of typical experiments : (a) experiments (1) and (2), (b) experiments (3) and (4)

10 Static stiffness in terms of the number of cycles:

○ Experiment (1), $\nabla$ Experiment (2), $\triangleright$ Experiment (3),

$\diamond$ Experiment (4)

11 Dynamic stiffness in terms of the number of cycles:

○ Experiment (1), $\nabla$ Experiment (2), $\triangleright$ Experiment (3),

$\diamond$ Experiment (4) 
12 Comparison between static and dynamic stiffnesses (experiment 3 ): ○ static stiffness, $\diamond$ dynamic stiffness

13 Maximum elastic displacements: o Experiment (1), $\nabla$ Experiment (2), $\triangleright$ Experiment (3), $\diamond$ Experiment (4)

15 Relation between the velocity and the elastic displacement, $o$ measurement, - interpolation

16 (a) Downward and (b) upward accelerations of sleepers

17 (a) Downward and (b) upward ballast accelerations

18 Settlement of the left sleeper versus the number of cycles for (a) $160 \mathrm{~km} \mathrm{~h}^{-1}$ and (b) $320 \mathrm{~km} \mathrm{~h}^{-1}$

19 Settlement of the left sleeper (a) and of the right sleeper (b) for the velocity $v=400 \mathrm{~km} \mathrm{~h}^{-1}$

20 Relation between the velocity and the settlement increment

21 Settlement increment versus the acceleration in ballast for (a) the downward acceleration and (b) the upward acceleration

22 Settlement increment versus the acceleration of the sleeper for (a) the downward acceleration and (b) the upward acceleration

23 Standard deviation versus the velocity for (a) the settlement increment and (b) the downward ballast acceleration 
24 Standard deviation of the settlement increment versus the acceleration in ballast for (a) the average downward and (b) the average upward accelerations

25 Standard deviation of the settlement increment versus the acceleration of a sleeper for (a) the average downward and (b) the average upward accelerations 


\section{List of Tables}

$1 \quad$ Scale factors. $\quad 61$

2 Values of the variables $X$ and $Y$. 62

$3 \quad$ Physical and mechanical characteristics of materials 63

4 Maximum elastic displacement at the left block of the central sleeper. 64

5 Maximum positive acceleration (upward) at the left block of the central sleeper. 


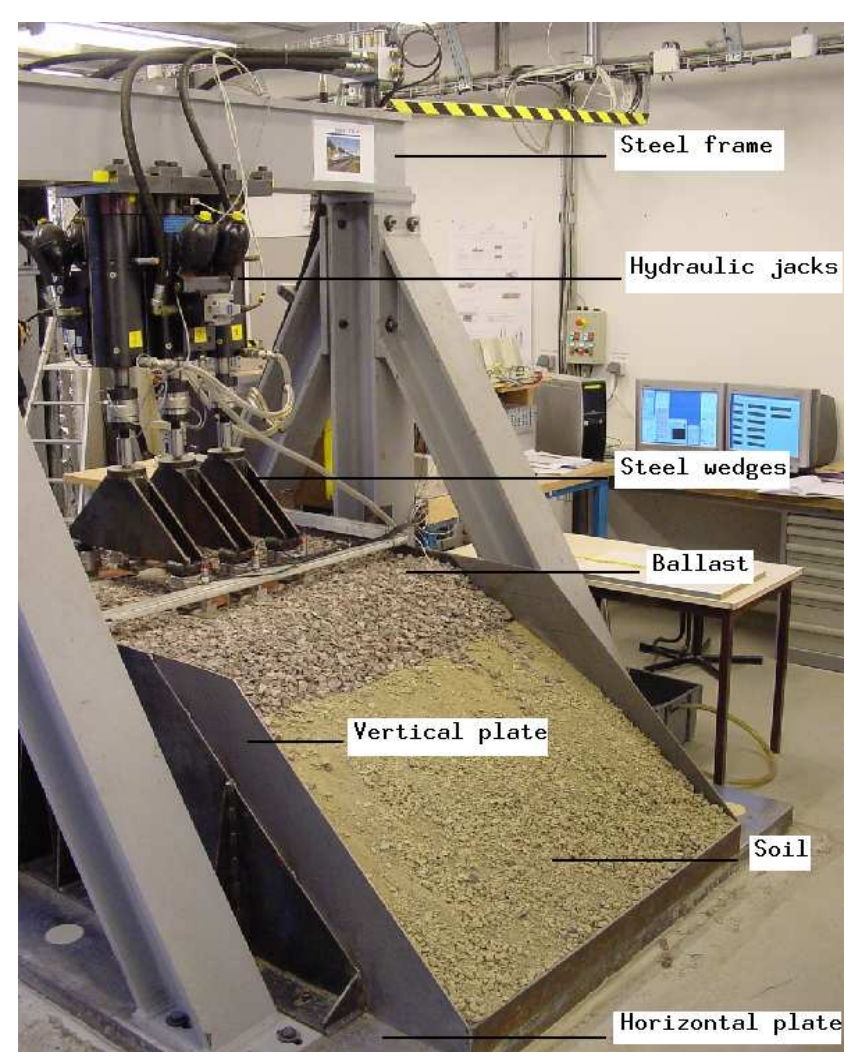

Fig. 1. Experiment at reduced scale 


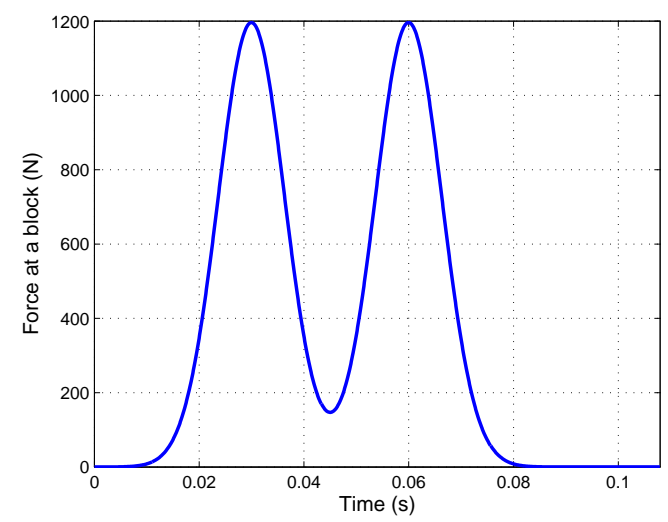

Fig. 2. Applied force at a block at reduced scale 


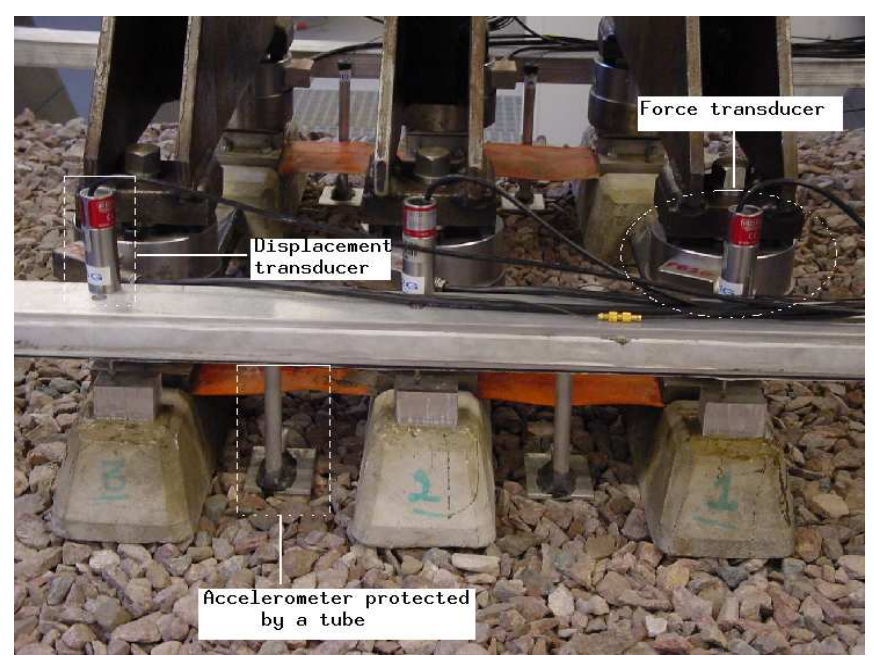

Fig. 3. Transducers 


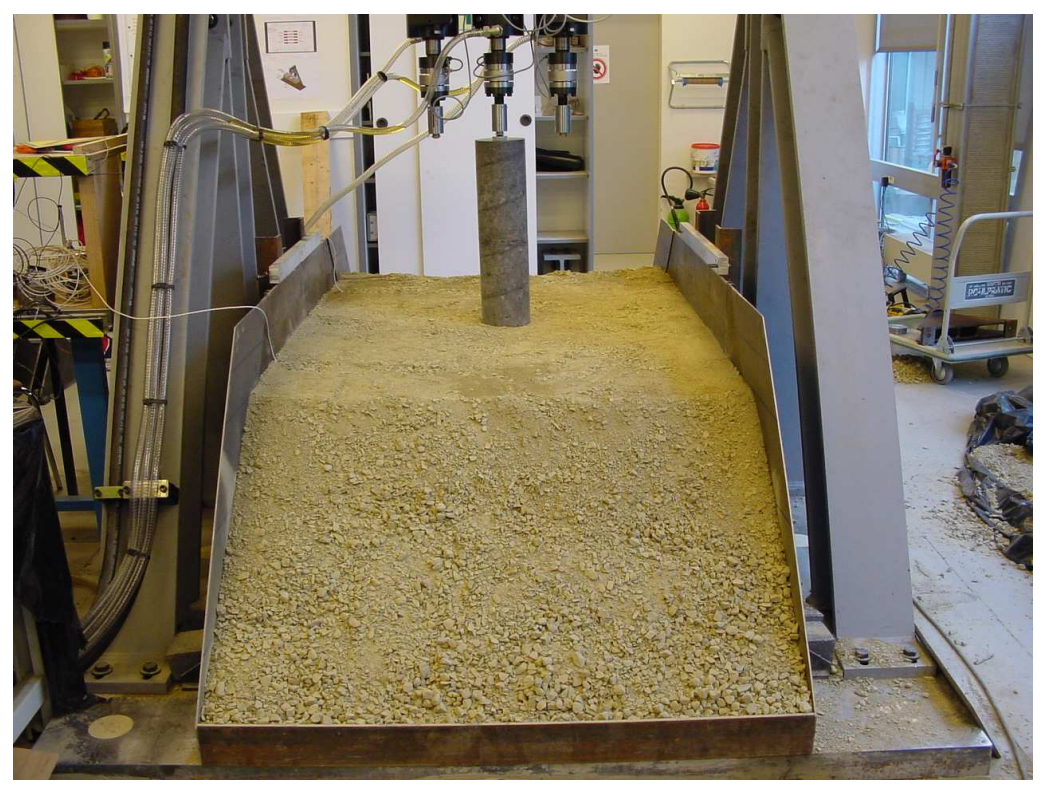

Fig. 4. Identification experiment on soil 


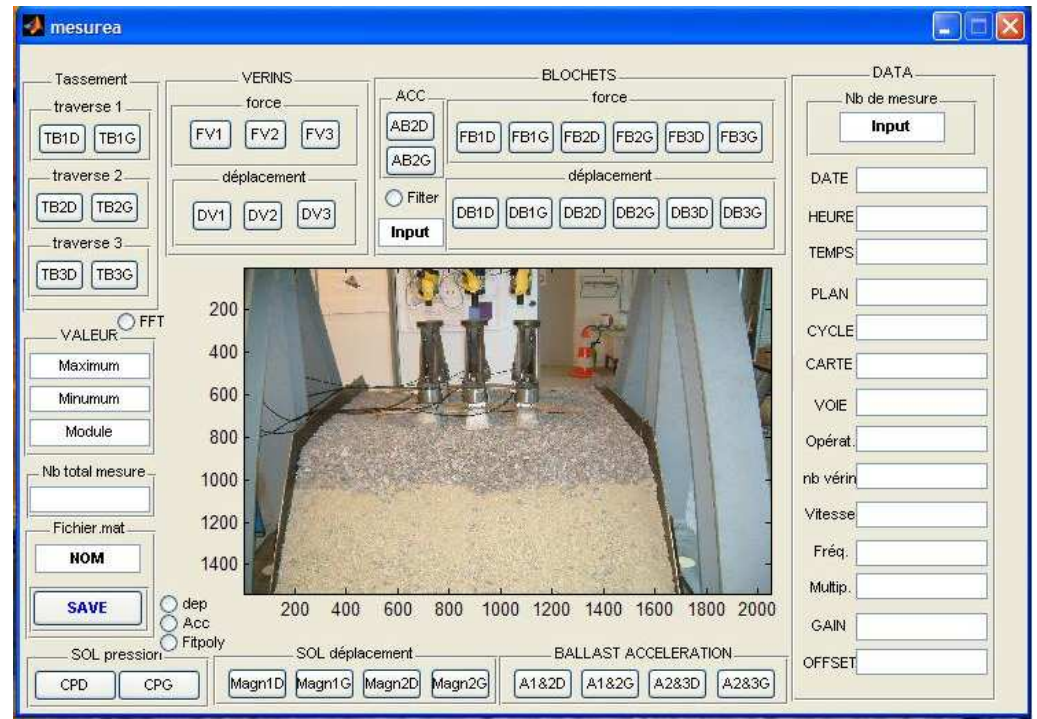

Fig. 5. Post-processing software 

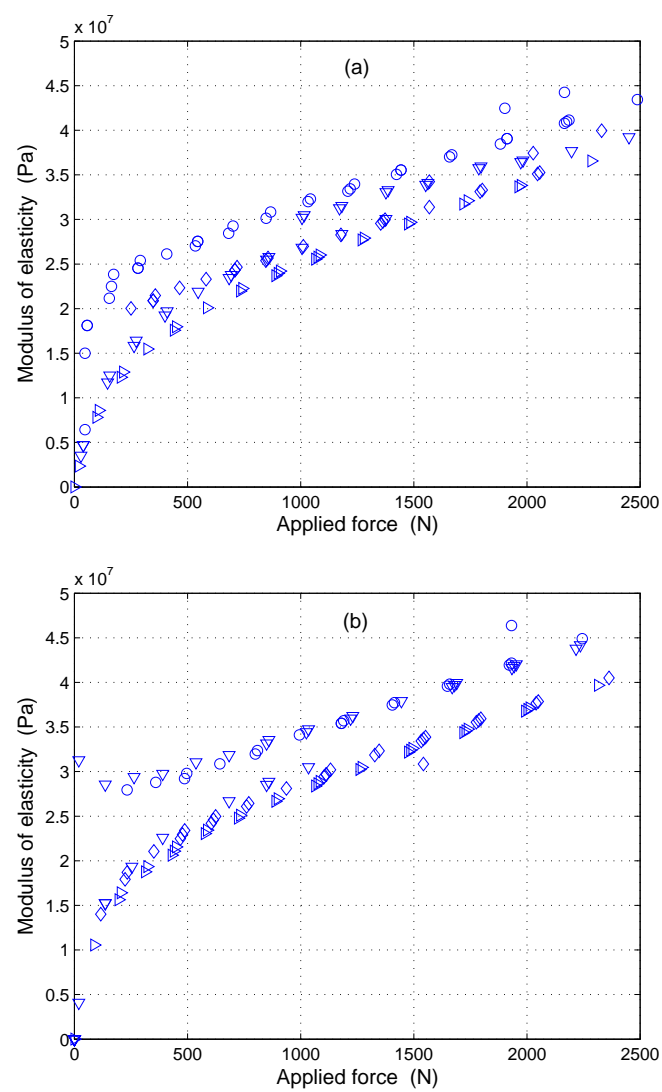

Fig. 6. Elasticity modulus of soil: (a) at the beginning of experiment, (b) at the end of experiment : $\circ$ Experiment (1), $\nabla$ Experiment $(2), \triangleright$ Experiment $(3), \diamond$ Experiment (4) 

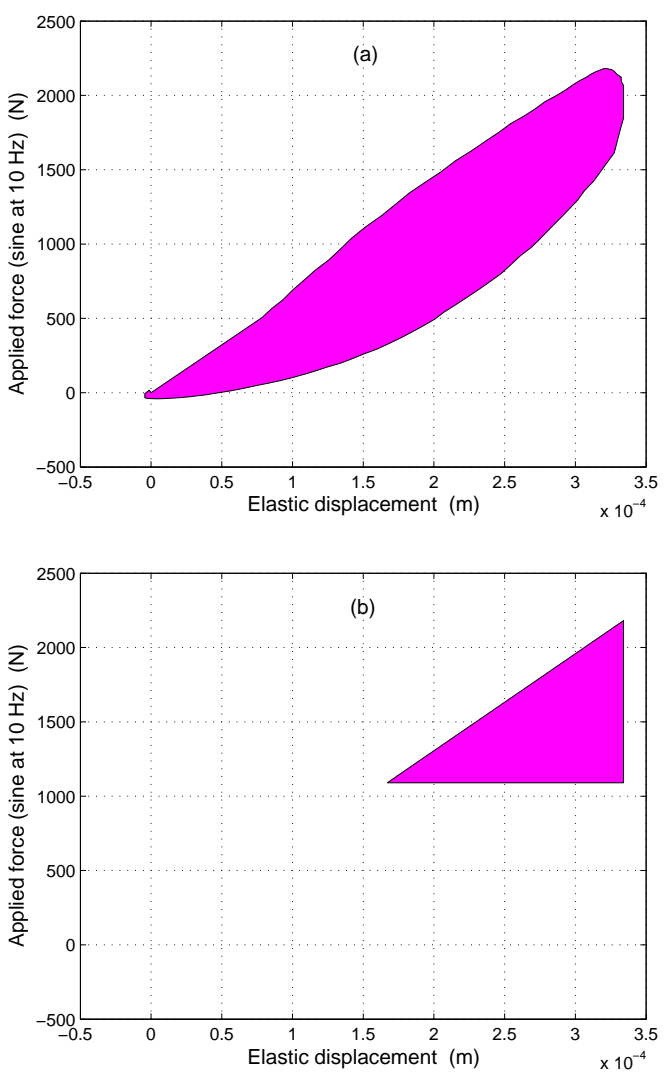

Fig. 7. (a): Dissipated energy per cycle, (b): Total energy of deformation 


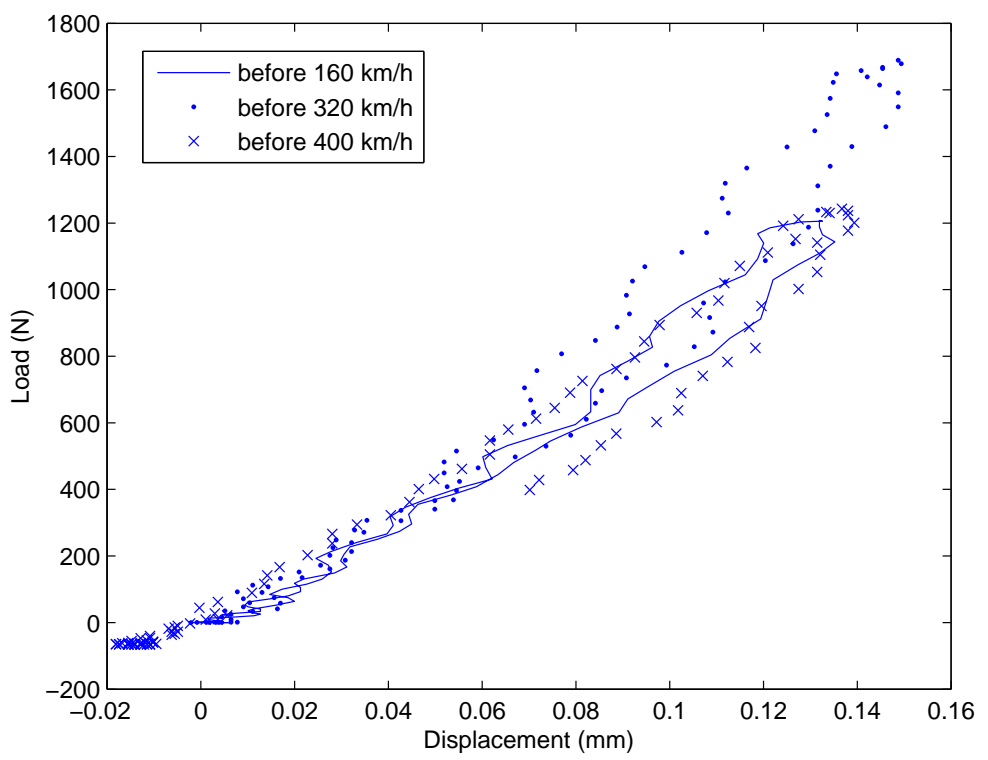

Fig. 8. Force displacement on the complete structure for static loads 
(a)

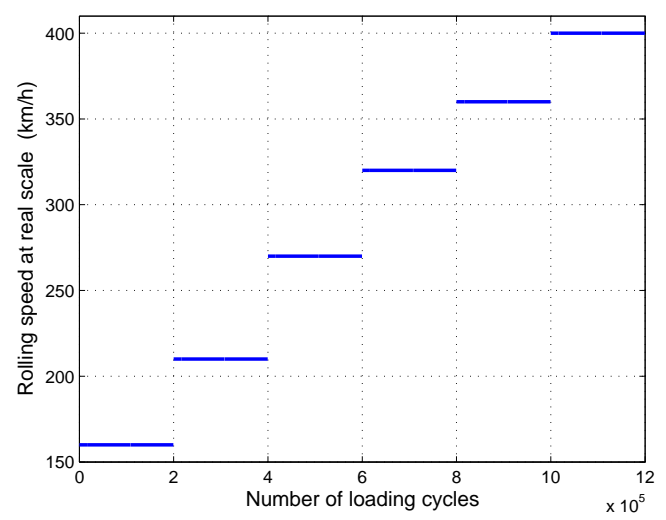

(b)

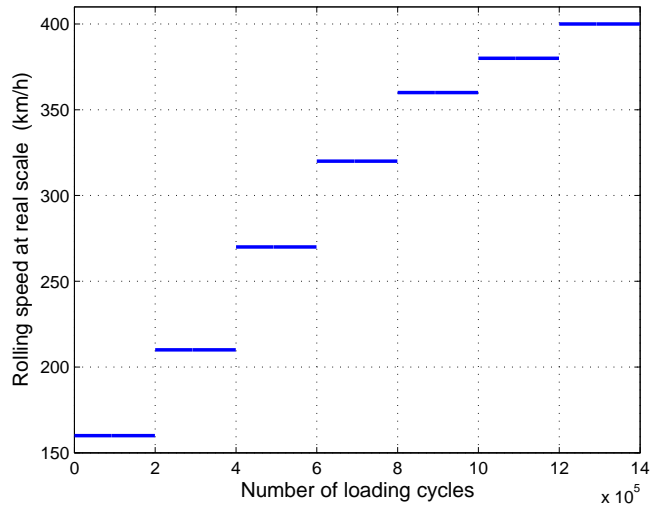

Fig. 9. Progress of typical experiments : (a) experiments (1) and (2), (b) experiments (3) and (4) 


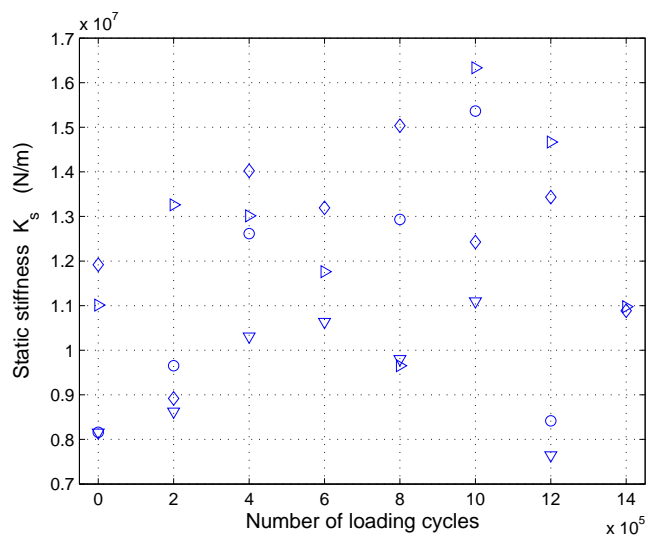

Fig. 10. Static stiffness in terms of the number of cycles: $\odot$ Experiment (1), $\nabla$ Experiment $(2), \triangleright$ Experiment $(3), \diamond$ Experiment $(4)$ 


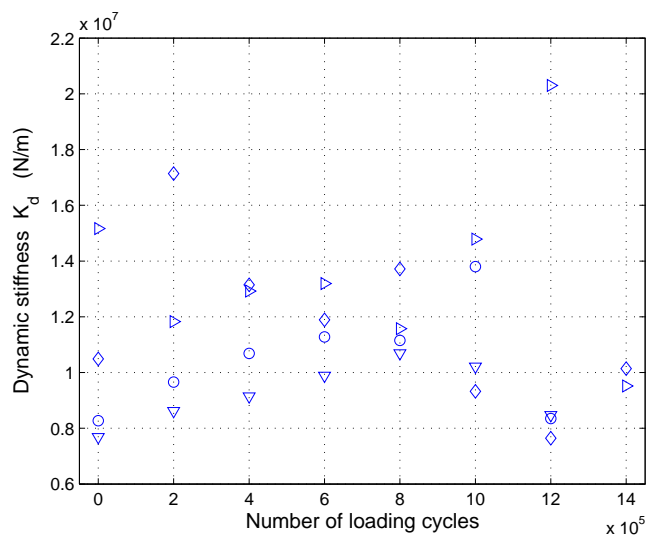

Fig. 11. Dynamic stiffness in terms of the number of cycles: $\circ$ Experiment (1), $\nabla$ Experiment $(2), \triangleright$ Experiment $(3), \diamond$ Experiment $(4)$ 


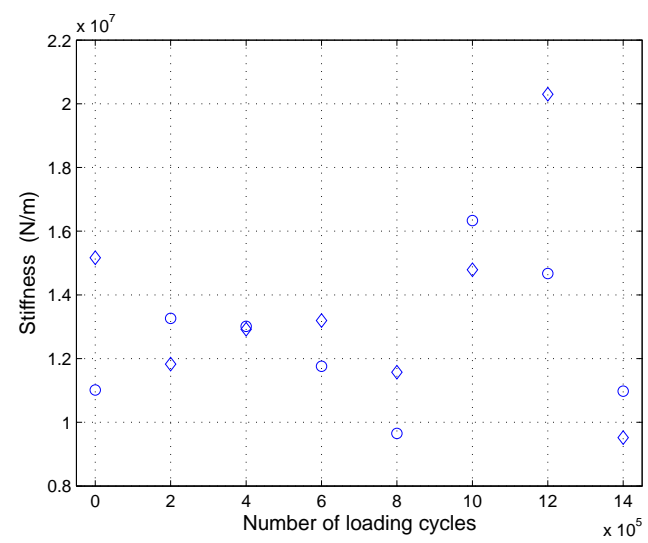

Fig. 12. Comparison between static and dynamic stiffnesses (experiment 3): o static stiffness, $\diamond$ dynamic stiffness 


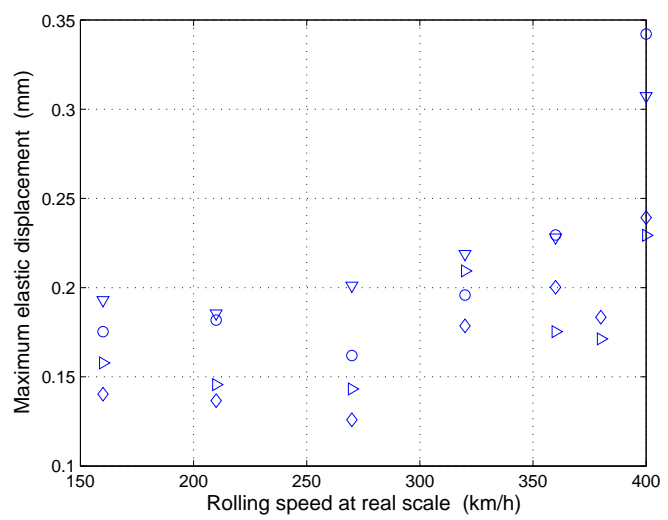

Fig. 13. Maximum elastic displacements: $\circ$ Experiment (1), $\nabla$ Experiment (2), $\triangleright$ Experiment $(3), \diamond$ Experiment $(4)$ 


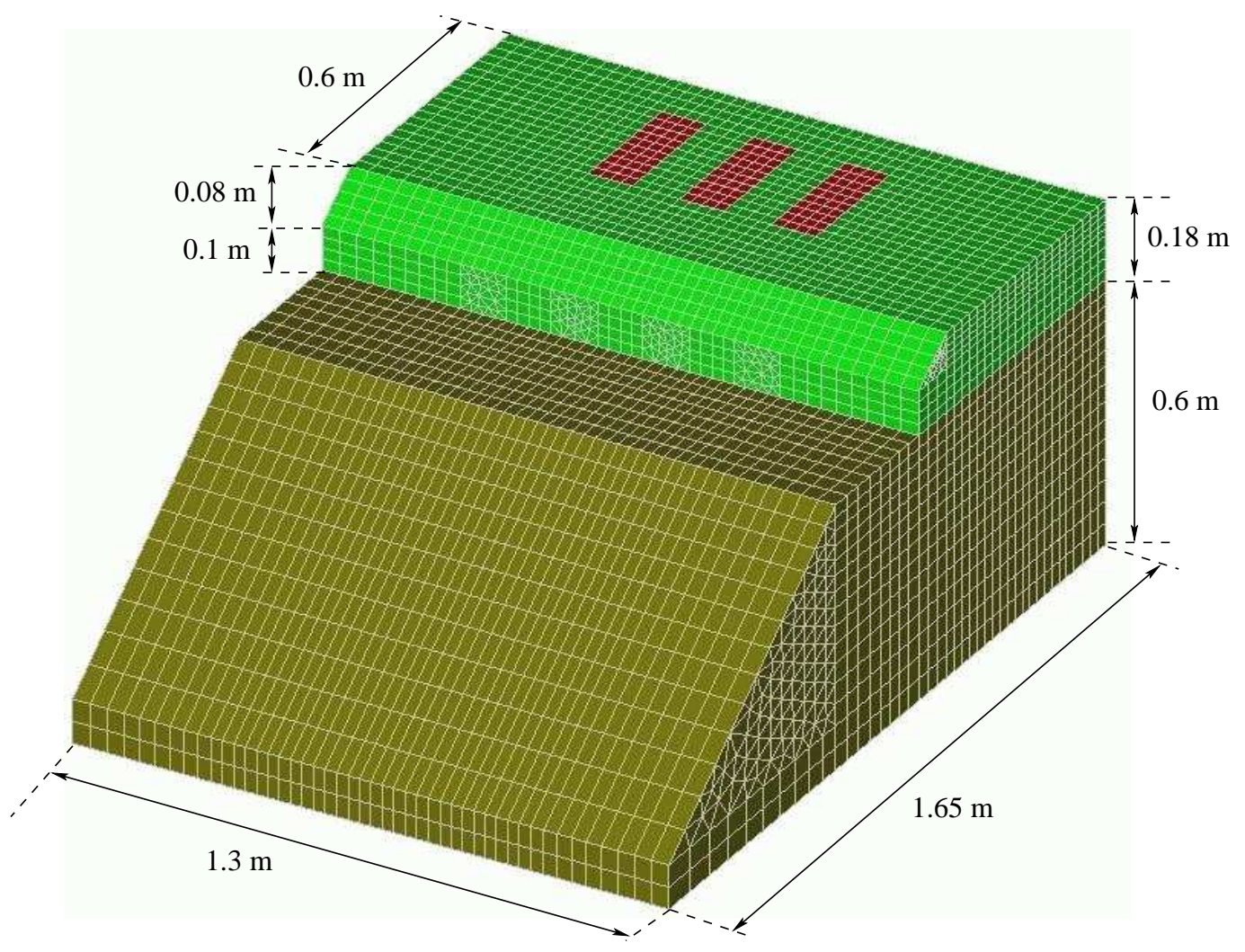

Fig. 14. Three-dimensional finite element model 


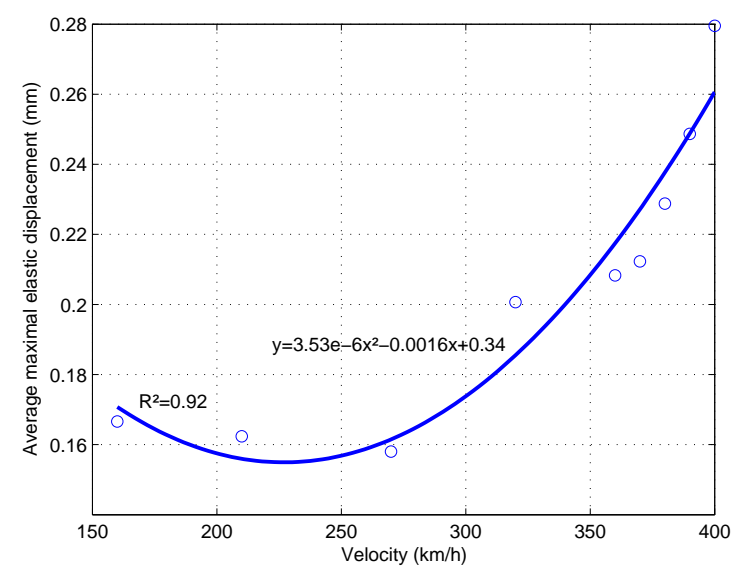

Fig. 15. Relation between the velocity and the elastic displacement, o measurement, - interpolation 
(a)

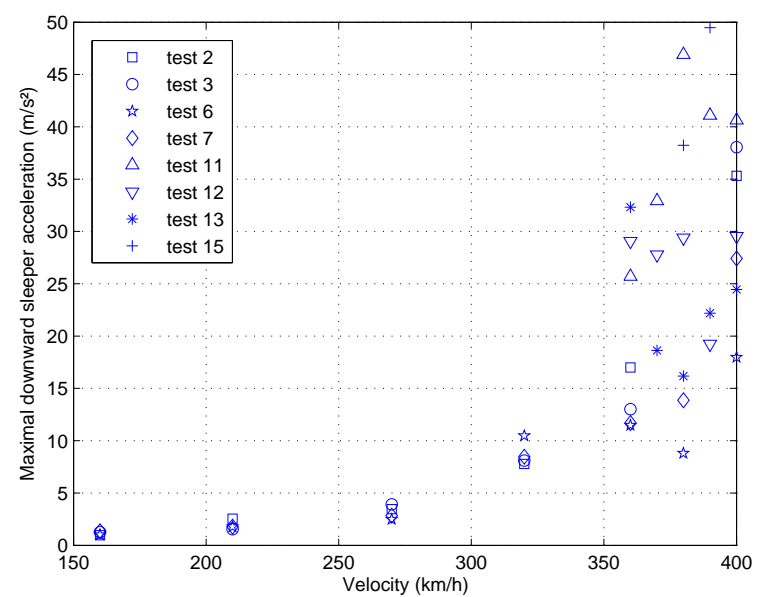

(b)

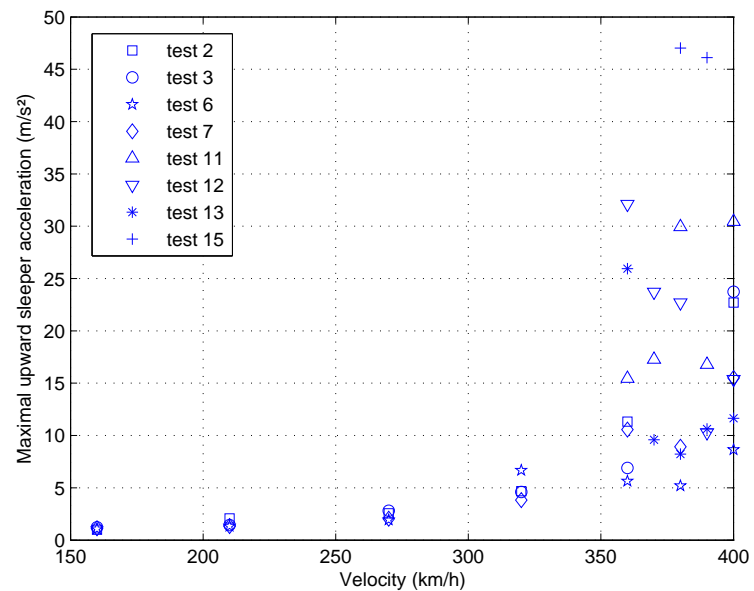

Fig. 16. (a) Downward and (b) upward accelerations of sleepers 
(a)

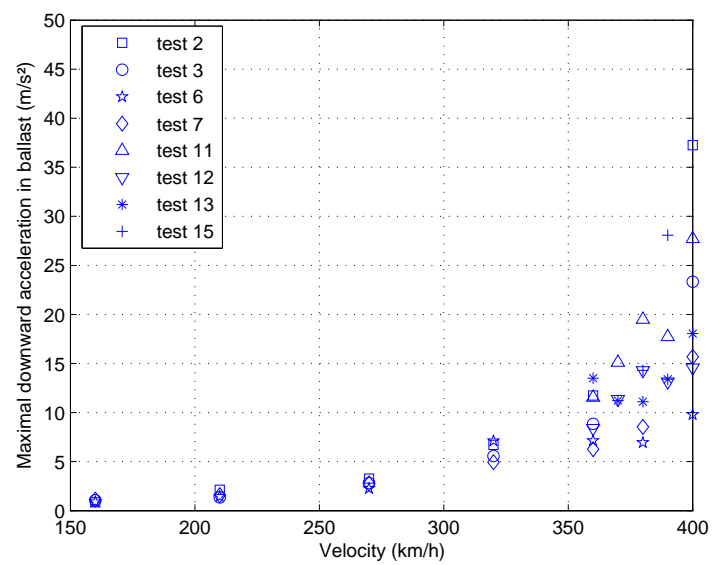

(b)

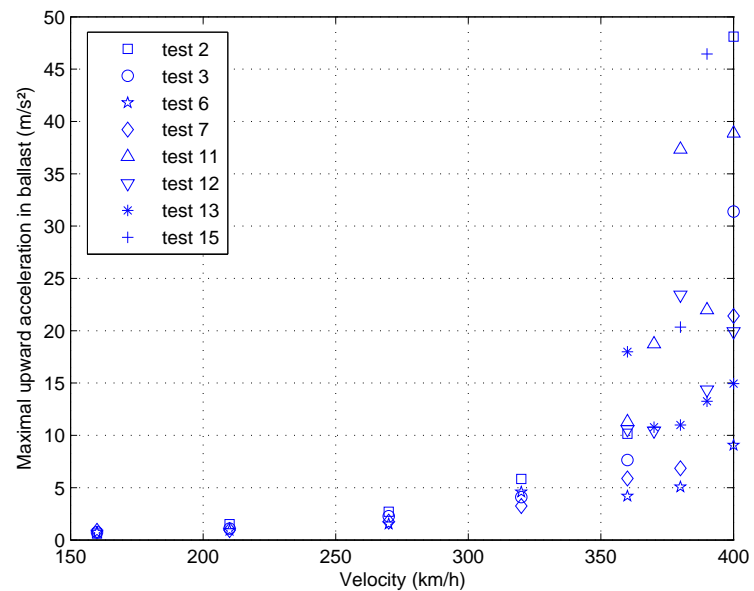

Fig. 17. (a) Downward and (b) upward ballast accelerations 
(a)

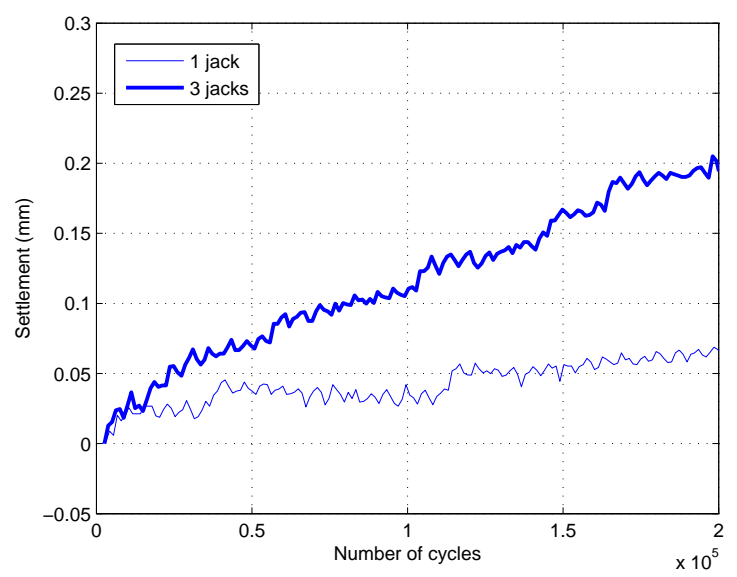

(b)

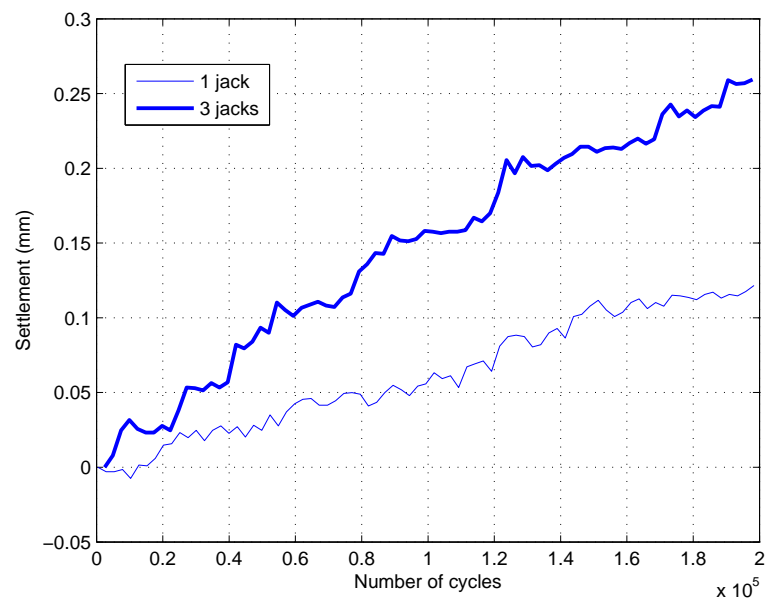

Fig. 18. Settlement of the left sleeper versus the number of cycles for (a) $160 \mathrm{~km} \mathrm{~h}^{-1}$ and (b) $320 \mathrm{~km} \mathrm{~h}^{-1}$ 
(a)

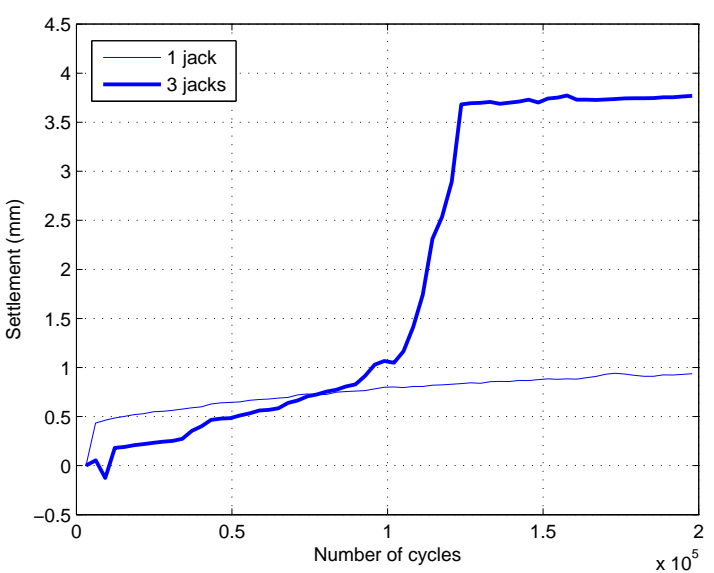

(b)

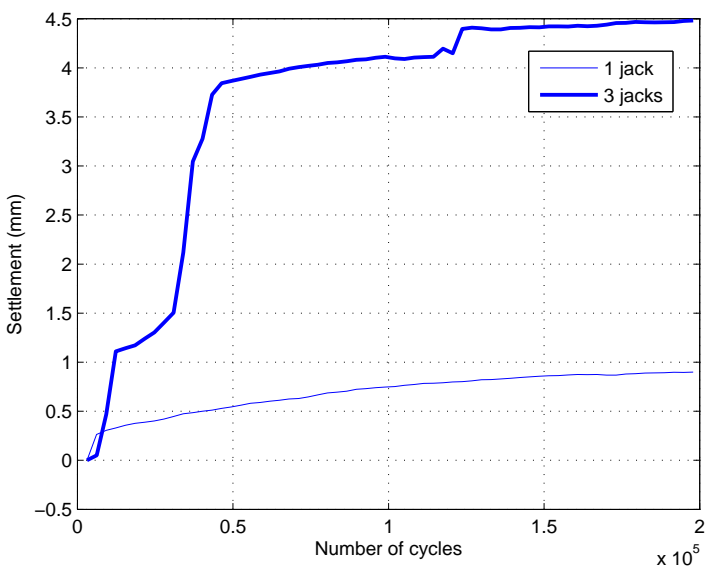

Fig. 19. Settlement of the left sleeper (a) and of the right sleeper (b) for the velocity $v=400 \mathrm{~km} \mathrm{~h}^{-1}$ 


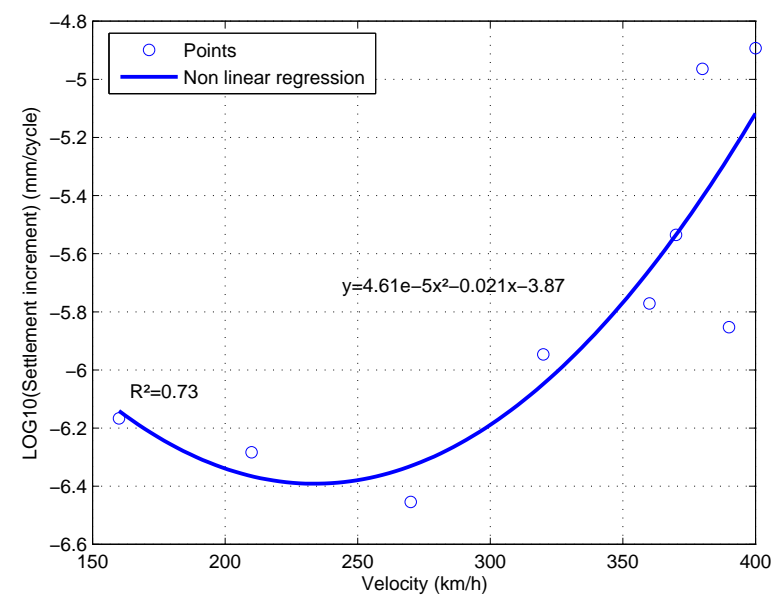

Fig. 20. Relation between the velocity and the settlement increment 
(a)

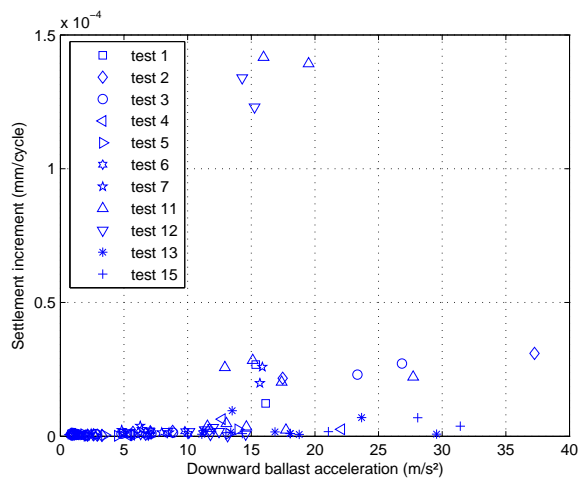

(b)

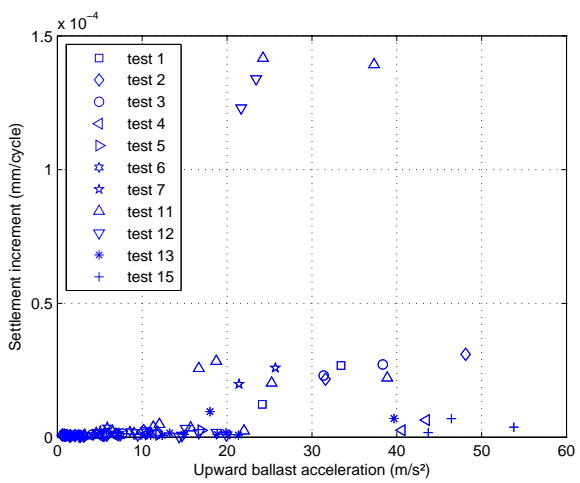

Fig. 21. Settlement increment versus the acceleration in ballast for (a) the downward acceleration and (b) the upward acceleration 
(a)

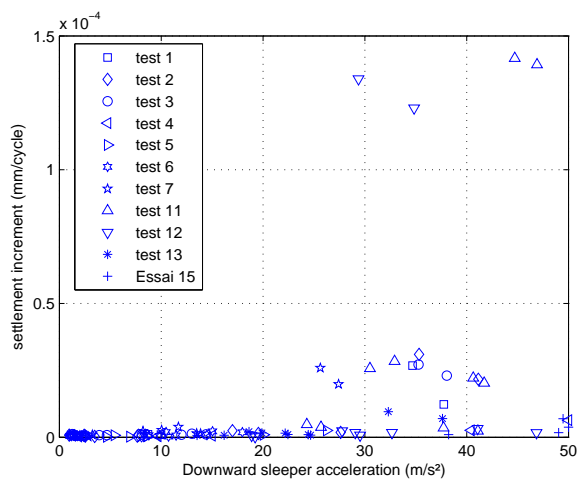

(b)

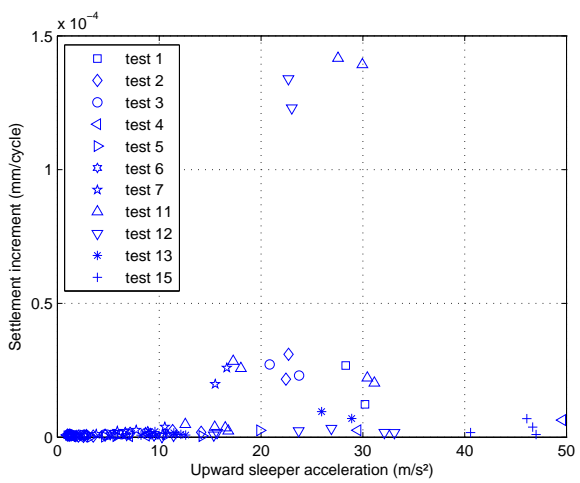

Fig. 22. Settlement increment versus the acceleration of the sleeper for (a) the downward acceleration and (b) the upward acceleration 
(a)

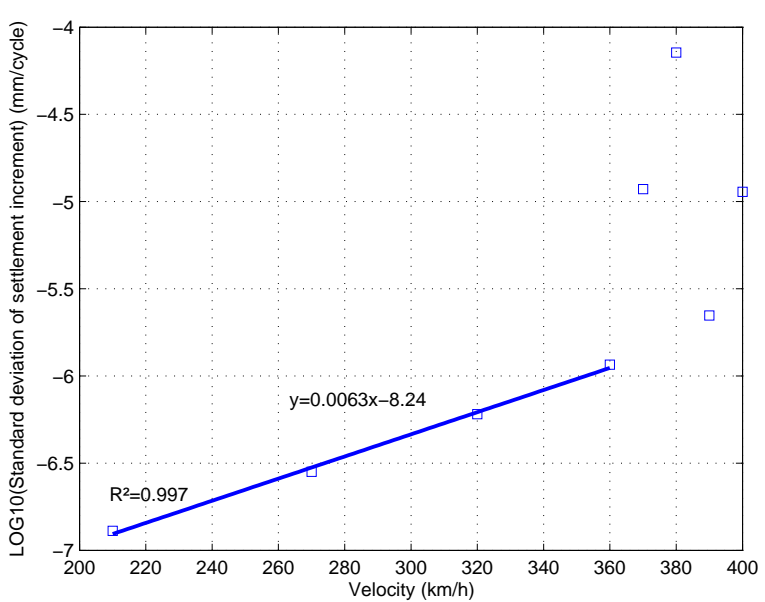

(b)

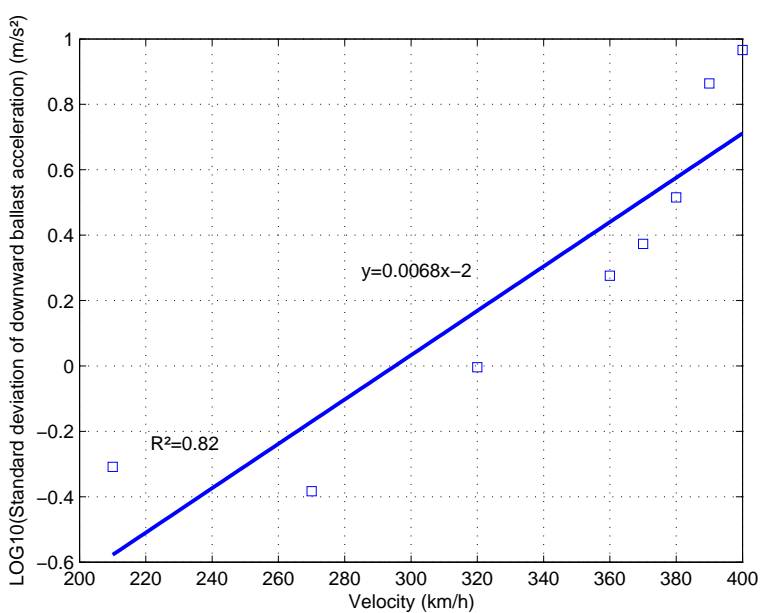

Fig. 23. Standard deviation versus the velocity for (a) the settlement increment and (b) the downward ballast acceleration 
(a)

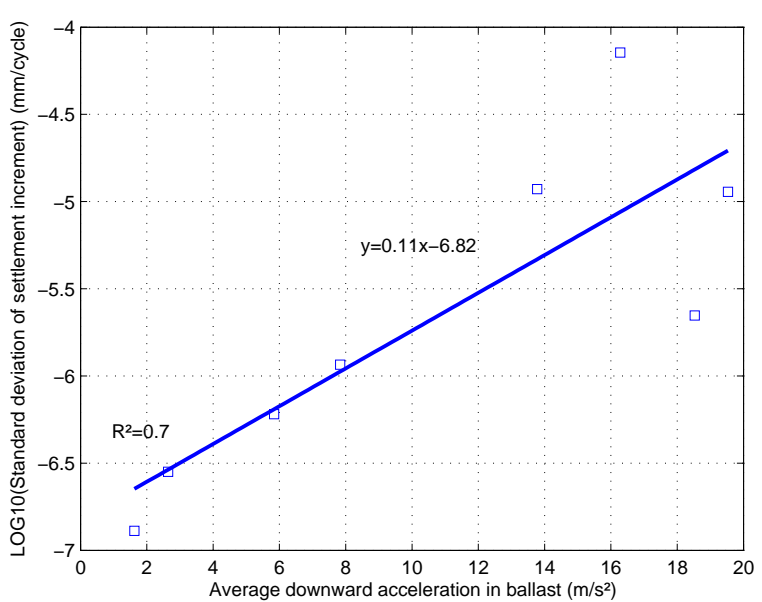

(b)

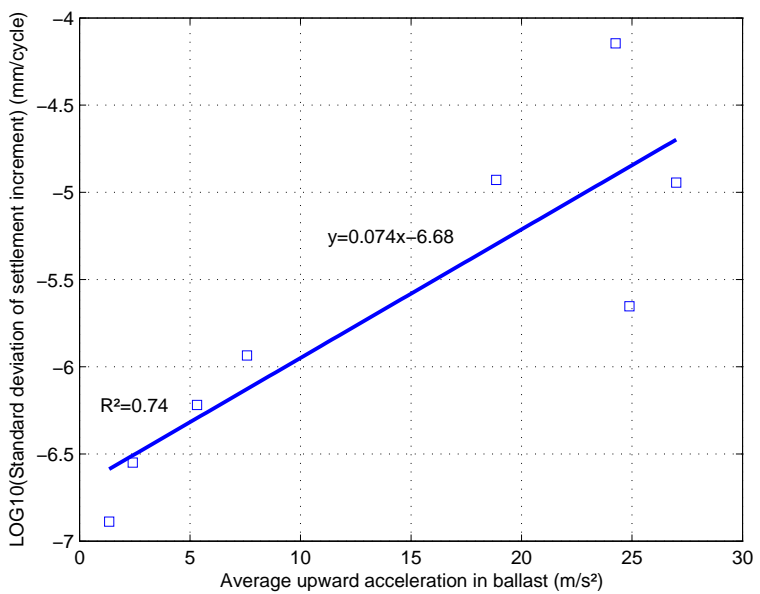

Fig. 24. Standard deviation of the settlement increment versus the acceleration in ballast for (a) the average downward and (b) the average upward accelerations 
(a)

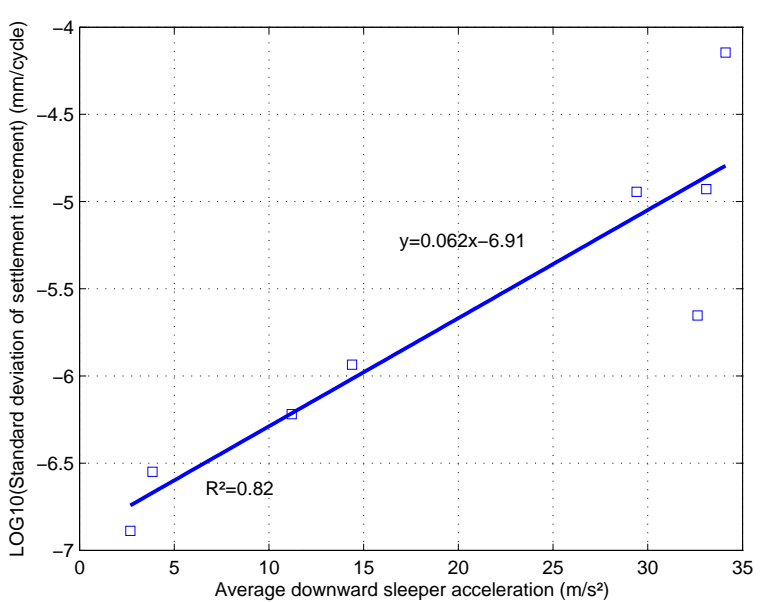

(b)

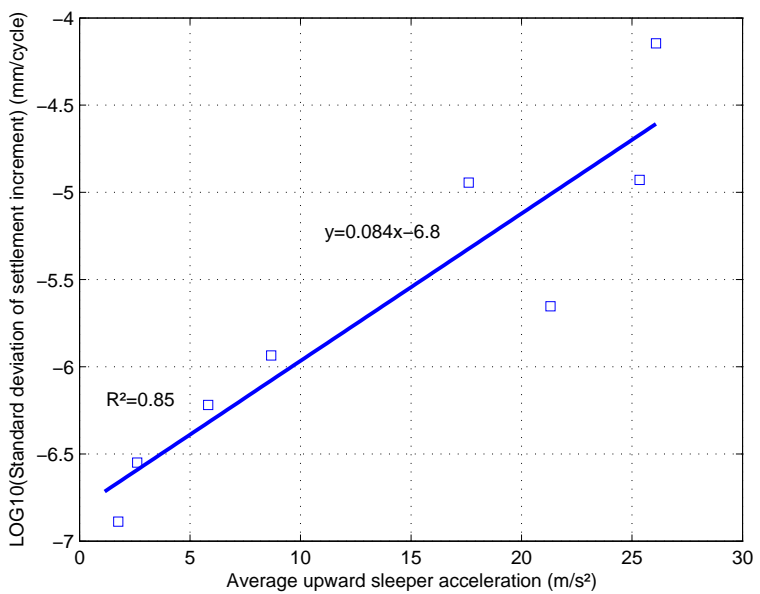

Fig. 25. Standard deviation of the settlement increment versus the acceleration of a sleeper for (a) the average downward and (b) the average upward accelerations 
Table 1

Scale factors.

Parameter Scale Factor Parameter Scale Factor

\begin{tabular}{cccc}
\hline Length & $1 / 3$ & Volume & $1 / 27$ \\
\hline Density & 1 & Mass & $1 / 27$ \\
\hline Acceleration & 1 & Force & $1 / 27$ \\
\hline Stress & $1 / 3$ & Speed & $1 / \sqrt{3}$ \\
\hline Time & $1 / \sqrt{3}$ & Frequency & $\sqrt{3}$ \\
\hline
\end{tabular}


Table 2

Values of the variables $X$ and $Y$.

\begin{tabular}{lccccc}
$E_{s}(\mathrm{MPa})$ & 10 & 30 & 60 & 80 & 100 \\
\hline$X$ & 0.82 & 0.715 & 0.64 & 0.625 & 0.61 \\
$Y$ & 0.23 & 0.32 & 0.38 & 0.41 & 0.43 \\
\hline
\end{tabular}


Table 3

Physical and mechanical characteristics of materials

\begin{tabular}{cccc} 
Material & $\rho\left(\mathrm{kg} \mathrm{m}^{-3}\right)$ & $E(\mathrm{MPa})$ & $\nu$ \\
\hline Reinforced concrete & 2500 & $2.5 \times 10^{2}$ & 0.2 \\
\hline Compacted ballast & 1700 & 200 & 0.4 \\
\hline Non compacted ballast & 1300 & 8 & 0.2 \\
\hline Soil & 2100 & 33 & 0.25 \\
\hline Steel & 7800 & $2.1 \times 10^{5}$ & 0.28 \\
\hline
\end{tabular}


Table 4

Maximum elastic displacement at the left block of the central sleeper.

\begin{tabular}{ccccc}
$F_{\max }(\mathrm{N})$ & $v\left(\mathrm{~km} \mathrm{~h}^{-1}\right)$ & measured & calculated $(\mathrm{CESAR})$ & relative error $(\%)$ \\
\hline 1656 & 160 & 0.1666 & 0.1875 & 12.5 \\
\hline 1717 & 210 & 0.1624 & 0.1751 & 8 \\
\hline 1799 & 270 & 0.158 & 0.211 & 33.5 \\
\hline 2033 & 320 & 0.2007 & 0.2381 & 18.6 \\
\hline 2172 & 360 & 0.2083 & 0.2517 & 21 \\
\hline 2460 & 400 & 0.2795 & 0.2811 & 0.6 \\
\hline
\end{tabular}


Table 5

Maximum positive acceleration (upward) at the left block of the central sleeper.

\begin{tabular}{ccccc}
$F_{\max }(\mathrm{N})$ & $v\left(\mathrm{~km} \mathrm{~h}^{-1}\right)$ & measured & calculated $(\mathrm{CESAR})$ & relative error $(\%)$ \\
\hline 1656 & 160 & 1.105 & 0.9467 & 14 \\
\hline 1717 & 210 & 1.546 & 1.704 & 10 \\
\hline 1799 & 270 & 2.337 & 3.426 & 46.6 \\
\hline 2033 & 320 & 4.943 & 5.459 & 10 \\
\hline 2172 & 360 & 8.606 & 8.352 & 8 \\
\hline 2460 & 400 & 17.65 & 16.29 & 8 \\
\hline
\end{tabular}

